\title{
A STAT3-NFkB/DDIT3/CEBPB axis modulates ALDH1A3 expression in chemoresistant cell subpopulations
}

\author{
Claudia Canino ${ }^{1}$ YuYing Luo ${ }^{2}$, Paola Marcato³, Giovanni Blandino ${ }^{4,5}$, Harvey I. \\ Pass $^{1}$ and Mario Cioce ${ }^{1}$ \\ ${ }^{1}$ Division of Thoracic Surgery, Department of Cardiothoracic Surgery, Langone Medical Center, New York University, New \\ York, USA \\ 2 New York University School of Medicine, New York, USA \\ 3 Department of Pathology and Department of Microbiology \& Immunology, Dalhousie University, Halifax, Nova Scotia, \\ Canada \\ ${ }^{4}$ Translational Oncogenomics Unit, Italian National Cancer Institute 'Regina Elena', Rome, Italy \\ ${ }^{5}$ Department of Oncology, Juravinski Cancer Center-McMaster University, Hamilton, Ontario, Canada \\ Correspondence to: Mario Cioce, email: Mario.Cioce@nyumc.org
}

Keywords: ALDH, STAT3, NFKB, DDIT3, CEBPB

Received: November 26, $2014 \quad$ Accepted: March 02, $2015 \quad$ Published: March 30, 2015

This is an open-access article distributed under the terms of the Creative Commons Attribution License, which permits unrestricted use, distribution, and reproduction in any medium, provided the original author and source are credited.

\section{ABSTRACT}

Here we studied the relevance and modulation of aldehyde dehydrogenase (ALDH) expression in malignant pleural mesothelioma (MPM) chemoresistant cell subpopulations (ALDH ${ }^{\text {bright }}$ cells), which survive pemetrexed + cisplatin treatment in vitro and in vivo. Expression of the ALDH1A3 isoform was invariably enriched in purified ALDH ${ }^{\text {bright }}$ cells from multiple MPM cell lines and accounted for the enzymatic activity of those cells. RNAi mediated downregulation of ALDH1A3 reduced the survival of the ALDH bright cells at steady state and, much more, after pemetrexed + cisplatin treatment. We demonstrated, for the first time, that a pSTAT3(tyr705)-NFkB(p65) complex is required for the repression of DDIT3 mRNA and this ensures high levels of CEBP $\beta$-dependent ALDH1A3 promoter activity. Inhibition of STAT3-NFkB activity allowed high levels of DDIT3 expression with increased formation of a DDIT3-CEBP $\beta$ complex. This reduced the occupancy of the ALDH1A3 promoter by CEBP $\beta$, thus largely reducing the ALDH1A3 expression. Consequently, survival of ALDH ${ }^{\text {bright }}$ cells in pemetrexed + cisplatin-treated cultures was impaired, following increased apoptosis. We show that such a mechanism is relevant in vivo and underlies the action of butein, a dual STAT3-NFkB inhibitor capable of abating the chemoresistance of mesothelioma cells in vivo. The possible broad translational relevance of the described mechanism is discussed.

\section{INTRODUCTION}

Malignant Pleural Mesothelioma (MPM) is a neoplastic disease whose challenging clinical management is characterized by silent progression, extremely low response rate to chemotherapy (pemetrexed + cisplatin) and poor prognosis [1-3]. There is an unmet need for better therapeutic options for such a fatal disease. We have recently shown that pemetrexed and cisplatin treatment of MPM cell lines and primary cultures triggered the emergence of cell subpopulations exhibiting absolute chemoresistance, mesenchymal traits and high levels of aldehyde dehydrogenase (ALDH) activity (ALDH ${ }^{\text {bright }}$ cells) [4] and those properties were shared by lung cancer ALDH ${ }^{\text {bright }}$ cells resistant to gefinitib and cisplatin [5]. The $\mathrm{ALDH}^{\text {bright }}$ cells represented, quantitatively, the main chemoresistant cell subpopulation in several other tumors and could be tracked by FACS-based assays [4, 6-8]. ALDHs are a family of enzymes with heterogeneous intracellular localization and substrate specificity, which function by oxidizing intracellular aldehydes to carboxylic acid, in physiological and patho-physiological conditions $[9,10]$. Additionally, ALDHs have been involved in 
conferring resistance to some alkylating agents [11, 12]. Enriched expression of ALDH isoforms has been observed in a conspicuous number of developmentally unrelated tumors [13-17]. For example, expression of the ALDH1A3 has been experimentally shown to modulate survival of melanoma and glioma cell subpopulations exhibiting properties of cancer stem cells $[18,19]$ and to promote pro-tumorigenic features in breast cancer cells [20]. Therefore, ALDHs can be therapeutically relevant targets in cancer [6].

Members of the CAAT/Enhancer-Binding Protein (CEBP) family were shown to modulate expression of the ALDH enzymes in different experimental settings, through binding to conserved CAAT binding site in proximity of the transcription start site [21-24]. On the other hand, the DDIT3/CHOP/GADD153 gene, whose levels are modulated by a plethora of stress stimuli [25], including chemotherapy $[26,27]$, was shown to modulate the CEBP $\beta$ transcriptional activity via protein-protein interactions in fibroblasts [25] and retinoic acid (RA) treated cells [22]. Notably, DDIT3 was shown to be modulated by STAT3 [28, 29].

The STAT3 pathway may modulate the number of NSCLC- and mesothelioma- ALDH ${ }^{\text {bright }}$ cells $[4,30]$ and, notably, glioma cells of the mesenchymal subtype, which require STAT3 (and CEBP $\beta$ ) for their survival [31], exhibited high levels of ALDH1A3 expression [19]. NFאB is constitutively active in most cancers [32] and exhibits extensive networking with several cancer signaling pathways, including STAT3 [33, 34]. We have shown that STAT3 and NFkB physically and functionally interacted in chemotherapy resistant MPM cell lines [35]. Treatment of MPM cell lines with butein (a multifunctional tetrahydroxychalcone), interfered with the stability of the STAT3-NFkB and this correlated with decreased chemoresistance in vitro and in vivo [35]. However, the molecular mechanism whereby interference with the STAT3-NFkB complex could affect MPM chemoresistance were not defined. Additionally, it was unclear whether this involved rearrangement of chemoresistant MPM cell subpopulations. Last but not least, it was not known which ALDH isoform(s) were expressed in the chemoresistant ALDH ${ }^{\text {bright }}$ MPM cells and the functional relevance of ALDH expression for those cell subpopulations.

By combining in vitro and in vivo approaches, we demonstrate here that a STAT3-NFkB-dependent repression of DDIT3 expression ensures high levels of CEBP $\beta$-dependent ALDH1A3 expression and that modulates the survival and resistance of the $\mathrm{ALDH}^{\text {bright }}$ cells to pemetrexed + cisplatin treatment in vitro and in vivo. Thus, we show that repression of DDIT3 levels may represent a cell subpopulation-specific mechanism of resistance to therapy which can be targeted in vivo by butein. Given the broad alteration of the STAT3 and NFkB signaling pathways in cancer $[32,36]$ and the presence of $\mathrm{ALDH}^{\text {bright }}$ cells in many neoplastic diseases, the conclusion of this study may be of broader relevance.

\section{RESULTS}

\section{Butein affects the survival of ALDH ${ }^{\text {bright }}$ cells after pemetrexed + cisplatin treatment}

Given that the ALDH ${ }^{\text {bright }}$ MPM cells are the main subcellular population resistant to pemetrexed [4] and given the ability of butein to counteract the chemoresistance of MPM cells in vitro and in vivo [35], we tested the hypothesis that the latter compound may affect the survival of the ALDH ${ }^{\text {bright }}$ cell subpopulations. Treatment with butein (B: $18 \mu \mathrm{M})$, alone or in combination with pemetrexed + cisplatin $(\mathrm{P}+\mathrm{C}: 10 \mu \mathrm{M}$ $+5 \mu \mathrm{M}$, respectively) for $96 \mathrm{hrs}$ strongly reduced the number of $\mathrm{ALDH}^{\text {bright }}$ cells in multiple unrelated MPM cell lines $(n=10)$ and prevented their increase after pemetrexed + cisplatin $(\mathrm{P}+\mathrm{C})$ treatment (Fig. 1A-1B, $p<$ $0.05)$. Since disappearance of ALDH ${ }^{\text {bright }}$ cells may follow direct enzyme inhibition or downregulation of ALDH expression, we explored which of the two processes underlied the effects of butein. Short term $(0-12 \mathrm{hrs})$ treatment of MPM cells with butein did not affect the ALDH activity (suppl. Fig. 1A, upper and lower). To assess whether butein may modulate the expression rather than the activity of ALDHs, we first determined which ALDH isoform(s) would be enriched in the ALDH ${ }^{\text {bright }}$ cells (Fig. 1C). We assessed (by quantitative PCR) the mRNA levels of the (detectable) ALDH isoforms in FACS sorted ALDH ${ }^{\text {bright }}$ and ALDH $^{\text {low }}$ cells from unrelated MPM cell lines (average purity of the ALDH ${ }^{\text {bright }}$ cells: $92-96 \%$, $\mathrm{n}=6$ ). Quantitative PCR revealed that the ALDH1A3 (and, to a much lesser extent, ALDH1A1 and ALDH2) was enriched in the ALDH ${ }^{\text {bright }}$ cells of all the analyzed cell lines $(p<0.05)$ (Fig. 1C, heat map).

\section{The ALDH1A3 isoform is responsible for the ALDH activity of the MPM cells}

Next, we infected MSTO-211H and HP-1 cells with shRNAs against ALDH2, ALDH1A1 and ALDH1A3, respectively (Fig. 1D, left). We found that only knocking down of ALDH1A3 correlated with a reduction of the ALDH $^{\text {bright }}$ cell number (Fig. 1D, right). Together this data (Figs. 1C and 1D) suggests that the ALDH1 A3 isoform is primarily responsible for ALDH activity of MPM cells. 


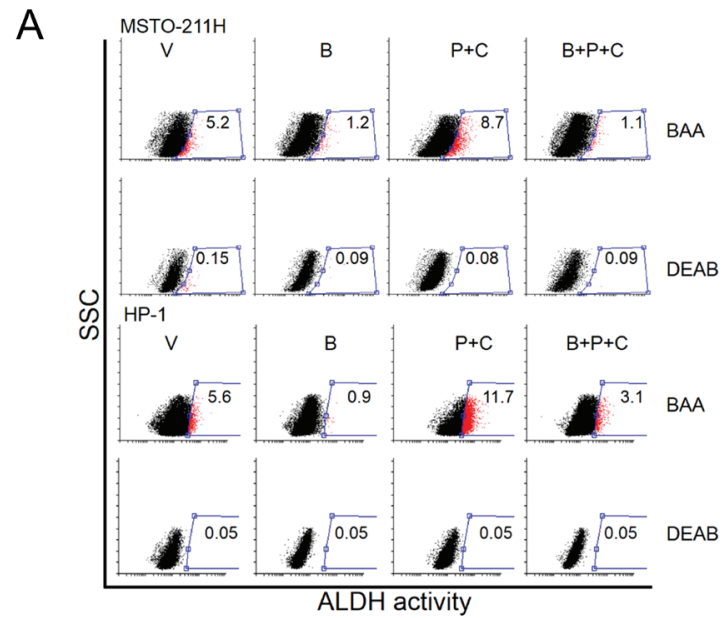

B

C
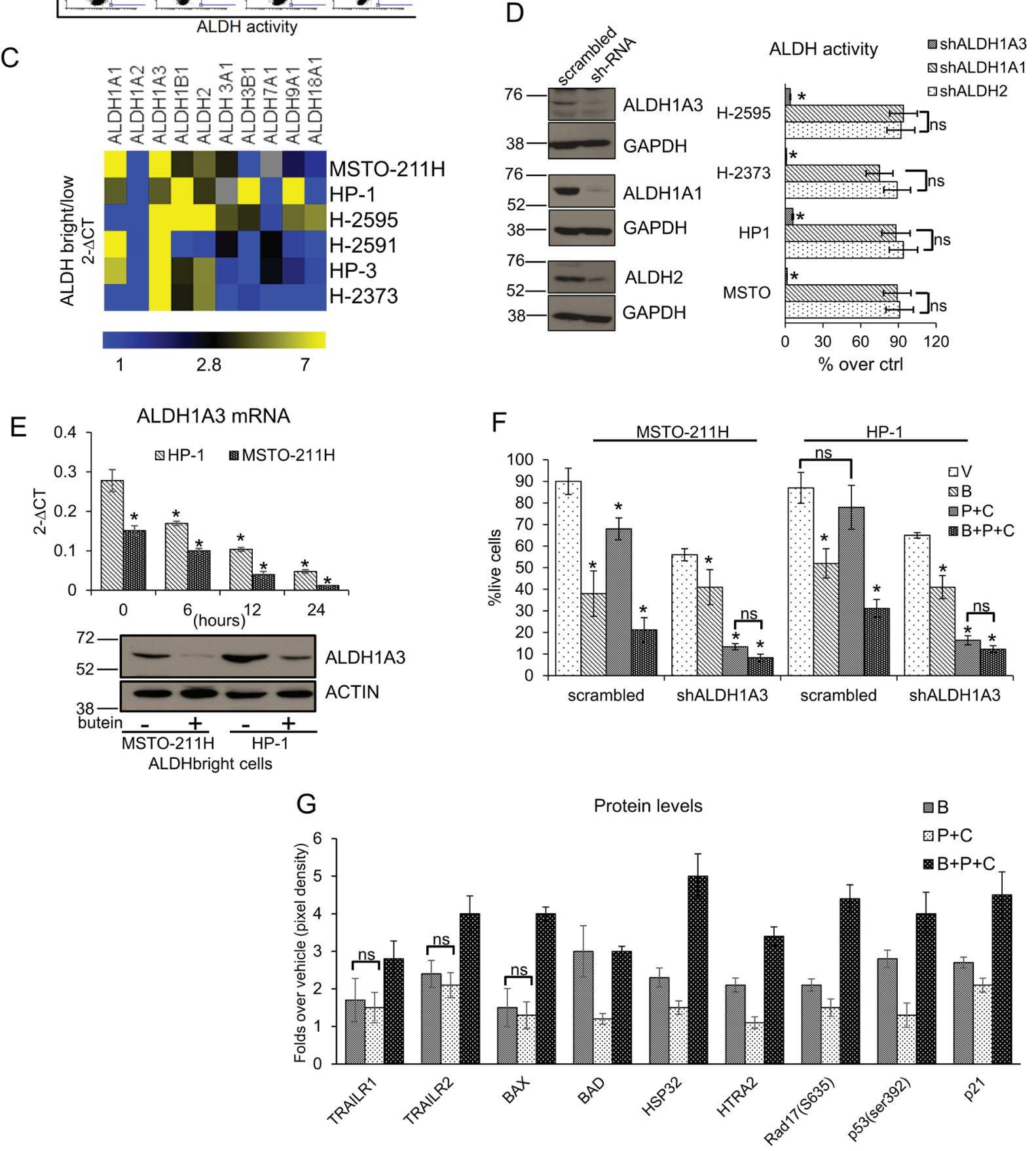
Figure 1: Butein affects the survival of MPM chemoresistant cell subpopulations (ALDH ${ }^{\text {bright }}$ cells). A. Butein reduces the number of ALDHbright cells in MPM cultures. Representative flow cytometry plots showing the percentage of ALDH ${ }^{\text {bright }}$ cells (red, gated) in MPM cell cultures treated for $24 \mathrm{hrs}$ with vehicle (V: DMSO 0.05\%) and butein $(\mathrm{B}: 18 \mu \mathrm{M})$, alone or in combination with pemetrexed + cisplatin ( $\mathrm{P}+\mathrm{C}: 10 \mu \mathrm{M}+5 \mu \mathrm{M}$, respectively) and stained for ALDH activity at $96 \mathrm{hrs}$. The percentage of ALDH ${ }^{\text {bright }}$ cells was determined over the same cells treated with a specific ALDH inhibitor (DEAB) immediately after adding the ALDH substrate (BAA). B. Graph showing the average $\mathrm{ALDH}^{\text {bright }}$ cell number from the grouped MPM cell lines $(\mathrm{n}=10)$ treated as indicated in 1A. C-D. The ALDH1A3 is responsible for the aldehyde dehydrogenase (ALDH) activity of the ALDHbright cells. C. Heat map: mRNA levels of the detectable ALDH isoforms in purified ALDH ${ }^{\text {bright }}$ and ALDH ${ }^{\text {low }}$ cells from 6 MPM cell lines. D. Left. Representative western blotting of MSTO-211H cells infected with a pool of ALDH1A1, ALDH2 and ALDH1A3 targeting shRNAs and control (scrambled) shRNAs, selected with puromycin and stained as indicated. Right. ALDH activity in 4 representative MPM cell lines infected as indicated in the left panel. Percentage of ALDH activity is relative to cells infected with the scrambled shRNA (control). Duplicate experiments. E. Butein modulates the expression of ALDH1A3. Upper. ALDH1A3 mRNA levels of purified MSTO-211H and HP-1 ALDH ${ }^{\text {bright }}$ cells treated with butein for the indicated times, as assessed by quantitative PCR. Lower. Western Blotting with anti-ALDH1A3 specific antibodies and anti-actin (as a loading control) of whole cell lysates from purified MSTO-211H and HP-1 ALDH ${ }^{\text {bright }}$ cells treated with butein for $36 \mathrm{hrs} \mathbf{F}-\mathbf{G}$. Butein treatment affects the viability of purified ALDHbright cells. Percentage of SYTOX red negative cells from MSTO-211H and HP-1 ALDH ${ }^{\text {bright }}$ cells infected with a vector expressing scrambled shRNA or ALDH1A3-shRNAs, respectively) and treated as indicated for $24 \mathrm{hrs}$ and harvested at $72 \mathrm{hrs}$. G. Protein levels of stress response genes and apoptotic effectors in the indicated MPM cell lines treated as in fig. 1F and harvested at $48 \mathrm{hrs}$. Duplicate experiments. Histogram bars represent the mean \pm s.e.m of $\geq$ three experiments, except were indicated otherwise. Statistics: $* p<0.05$; ns=not significant: $(p>0.05)$. One-way analysis of variance with Tukey's post hoc corrections-comparing the mean of each group with the mean of every other group (B) or Student's t-test (comparing each sample to its control or, when indicated, to other samples within the same group) (D, E. F. G).

\section{Butein downregulates the expression of ALDH1A3 thereby affecting the viability of the MPM ALDH ${ }^{\text {bright }}$ cells}

Quantitative PCR analysis of RNA extracted from FACS sorted $\mathrm{ALDH}^{\text {bright }}$ cells revealed that butein treatment triggered a strong, time dependent, downregulation of the of ALDH1A3 mRNA levels (Fig. $1 \mathrm{E}$, upper panel), in agreement with our hypothesis that butein affects the expression rather than the activity of the ALDH enzyme(s). This paralleled a sharp decrease, in the same cells, of the protein levels (lower panel, Fig. 1E). To detail the fate of ALDH ${ }^{\text {bright }}$ cells treated with butein and its relationship with the levels of ALDH1A3, we evaluated the viability of MSTO-211H and HP-1 cells treated with vehicle (V), butein (B), in absence or presence of pemetrexed + cisplatin treatment $(\mathrm{P}+\mathrm{C}$ vs $\mathrm{B}+\mathrm{P}+\mathrm{C}$, respectively) and upon RNAi-mediated downregulation of ALDH1A3 (Fig. 1F). SYTOX red staining revealed that the $(\mathrm{P}+\mathrm{C})$ treatment marginally affected the viability of the control vector-infected cells (as compared to the vehicle-treated cells), in line with the increased resistance of the ALDH ${ }^{\text {bright }}$ cells to these treatments [4]. Co-treatment with butein $(\mathrm{B}+\mathrm{P}+\mathrm{C})$ strongly increased the effect of the $\mathrm{P}+\mathrm{C}$ treatment on the same cells (Fig. 1F). In the same conditions, downregulation of ALDH1A3 strongly mimicked the effect of butein and did not significantly increase the effect of butein treatment (Fig. 1F), suggesting that modulation of ALDH1A3 levels is the main mechanism mediating the effect of butein on the viability of the ALDH ${ }^{\text {bright }}$ cells. Probing of an apoptosis antibody array with whole cell lysates from HP-1 ALDH ${ }^{\text {bright }}$ cells treated with $\mathrm{B}, \mathrm{P}+\mathrm{C}$ or with $\mathrm{B}+\mathrm{P}+\mathrm{C}$ confirmed increased levels, in the $\mathrm{B}+\mathrm{P}+\mathrm{C}$ treated cells (as compared to $\mathrm{B}$ and $\mathrm{P}+\mathrm{C}$ treated samples- $p<0.05$ ), of multiple apoptotic effectors: TRAILR1 (DR4) and TRAILR2 (DR5); BAX and BAD and the mitochondriareleased HTRA2 (Fig. 1G). Notably, some DNA damage and stress response genes were also upregulated with a similar trend (Fig. 1G).

\section{Butein downregulates the activity of the ALDH1A3 promoter}

To investigate the modulation of ALDH1A3 mRNA by butein (Fig. 1E), we transfected MSTO-211H and HP-1 MPM cells with a luciferase reporter vector containing the ALDH1 A3 promoter (from -900 to $+170 \mathrm{bp}$ ). Treatment of the cells with vehicle or butein $24 \mathrm{hrs}$ later revealed that the latter strongly downregulated the luciferase expression in a time dependent way (Fig. 2A).This experiment suggested that butein may directly affect the ALDH1A3 mRNA levels by modulating its promoter activity.

\section{Butein treatment reduces the binding of CEBP to the endogenous ALDH1A3 promoter}

A CAAT box (a consensus for the binding of the CEBP $\beta$ transcription factor), was shown to be crucial for the promoter activity of several ALDH family members $[21,22]$ and in house bioinformatics analysis $\left(\mathrm{MATCH}^{\mathrm{TM}}\right.$, BIOBASE) revealed that the ALDH1A3 promoter contained a conserved CAAT box (-50/-36bp from the transcription start site). Quantitative PCR analysis of chromatin immunoprecipitation (CHIP) with anti-CEBP $\beta$ antibodies from MSTO-211H and HP-1 cells revealed effective occupancy of the CEBP $\beta$ - binding site in vehicletreated cells (as compared to a isotype-matched rabbit $\mathrm{IgG})$. Butein treatment strongly reduced the occupancy of the CEBP $\beta$ binding site by CEBP $\beta$ (Fig. 2B). This 


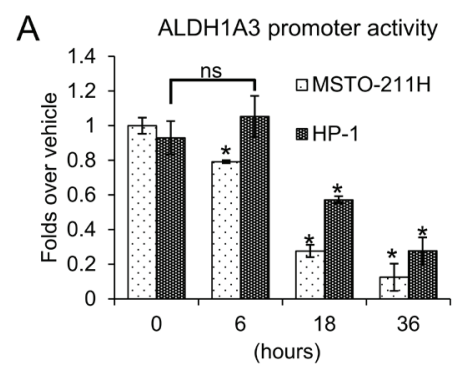

C
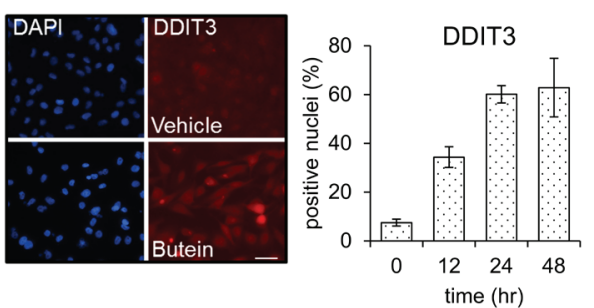

E

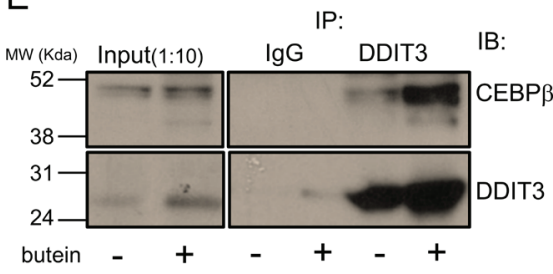

B

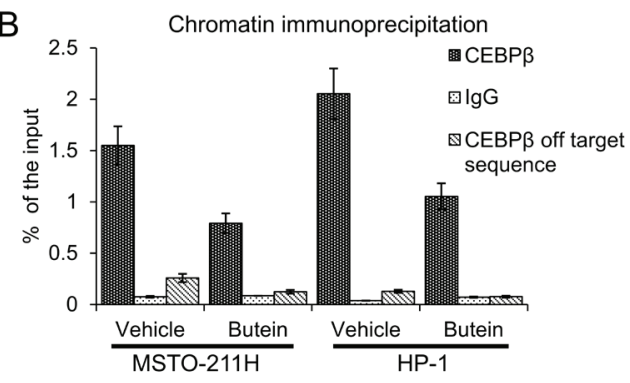

$\mathrm{D}$

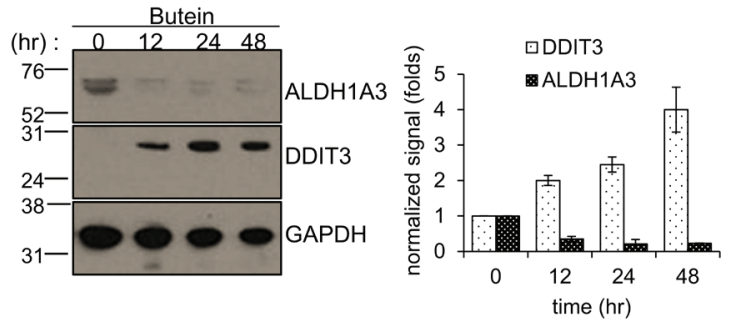

ALDH1A3 mRNA

$\mathrm{F}$

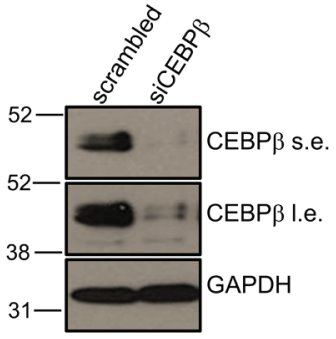
口scrambled siRNA

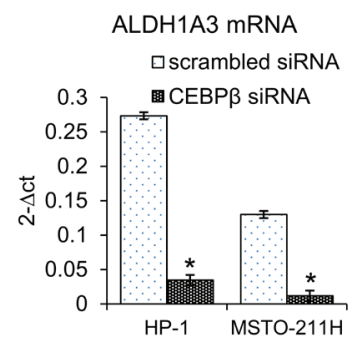

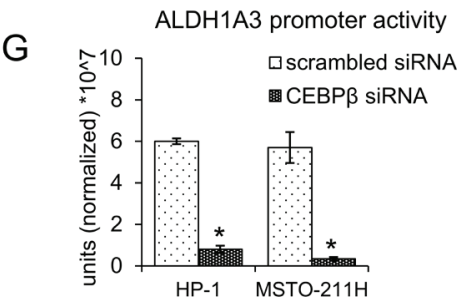

Figure 2: A. Butein modulates the ALDH1A3 promoter activity by modulating DDIT3 levels. Normalized luciferase activity of MSTO$211 \mathrm{H}$ and HP-1 cells transfected with a ALDH1A3-luciferase expressing vector and treated with butein $(18 \mu \mathrm{M})$ at the indicated times. B. Butein treatment reduces the occupancy of the ALDH1A3 promoter by CEBP $\beta$. Quantitative PCR. Amplification of the CEBP $\beta$ binding region from chromatin immunoprecipitated with anti-CEBP $\beta$ and control rabbit IgG from MSTO-211H and HP-1 cells treated with vehicle or butein $(18 \mu \mathrm{M})$, respectively, for 18 hours. Percentage of enrichment relative to the input chromatin is reported. Amplification of a DNA sequence not containing the CEBP $\beta$ binding site was used as an "off target" control to probe the anti-CEBP $\beta$ immunoprecipitated material. C-D. Butein affects DDIT3 protein levels. C. Left. Representative fluorescence micrographs of MSTO-211H cells treated with vehicle or butein $(18 \mu \mathrm{M})$, for $24 \mathrm{hrs}$ and stained with anti-DDIT3 antibodies (right). Cell nuclei were stained with DAPI (left). A minimum of 8 fields (containing $\geq 40$ nuclei) was counted in duplicate experiments. Scale bar: $20 \mu \mathrm{m}$. Right. Histograms showing the average percentage of DDIT3 positive nuclei from duplicate experiments. D. Left. Western blotting of whole cell lysates from MSTO-211H cells treated with butein $(18 \mu \mathrm{M})$, as indicated and stained with anti-DDIT3, anti-ALDH1A3 and anti-GAPDH antibodies (as a loading control). Right. Histograms showing the changes in intensity signal of DDIT3 and ALDH1A3 (normalized to actin with Image J software). E. Increased interaction of DDIT3 and CEBP $\beta$ in butein-treated cells. Western Blotting with anti-DDIT3 and anti CEBP $\beta$ antibodies of whole cell lysates immunoprecipitated with anti-DDIT3 antibody and isotype matched mouse IgG (as a control), respectively. F. RNAi-mediated downregulation of CEBP $\beta$ mimicks the effects of butein on ALDH1A3 expression. Left. Western blotting with anti- CEBP $\beta$ antibodies of MSTO-211H and HP-1 cells transfected with control (scrambled) and CEBP $\beta$-targeting siRNA. (s.e: short exposure; l.e.: long exposure). GAPDH used as a loading control. Right. mRNA levels of ALDH1 A3 in HP-1 and MSTO-211H cells transfected with scrambled or CEBP $\beta$ targeting siRNAs assessed by quantitative PCR. G. Luciferase activity of HP-1 and MSTO-211H cells transfected with an ALDH1A3 luciferase expression vector and, $24 \mathrm{hrs}$ later, with scrambled or CEBP $\beta$-targeting siRNAs. Histogram bars represent the mean \pm s.e.m of $\geq$ three experiments, except were otherwise indicated. Statistics: $* p<0.05$; ns $=$ not significant: $(p>0.05)$. Student's t-test (comparing each sample to its control or, when indicated, to other samples within the same group). 
strongly correlated with the effect of the drug on the ALDH1A3mRNA and protein levels (Fig. 1E). CEBP $\beta$ transcriptional activity is modulated through proteinprotein interactions involving several transcription factors, including the stress response DDIT3/CHOP/GADD153, formerly identified as both a modulator of CEBP $\beta$ activity and a stress responsive factor (including chemotherapy) [25].

\section{Butein affects DDIT3 mRNA and protein levels by modulating the DDIT3 promoter}

Thus, we investigated whether butein treatment may alter the levels of DDIT3 and whether this may interfere with CEBP $\beta$ activity. Butein treatment increased the levels of DDIT3 mRNA over time in two representative MPM cell lines (Suppl. Fig. 2) and this matched increased levels of the protein, as shown by indirect immunofluorescence and by western blotting (Fig. 2C-D). Additionally, increased levels of DDIT3 matched decreased amount of ALDH1A3 in the treated cells (Fig. 2D).

\section{Increased binding of DDIT3 to CEBP $\beta$ in butein- treated cells}

Given the ability of DDIT3 to negatively modulate CEBP $\beta$ transcriptional activity via protein-protein interactions [22, 25], we immunoprecipitated DDIT3 from unfractionated extracts of vehicle- and buteintreated MSTO-211H (and HP-1) cells (Fig. 2E). Western blotting of the immunoprecipitated material readily detected increased amounts of CEBP $\beta$ bound to DDIT3 upon butein treatment, suggesting that the increased DDIT3 in the butein treated cells interacted more or more strongly with CEBP $\beta$ (Fig. 2E). This strictly correlated with the observed decreased amount of CEBP $\beta$ bound to the ALDH1A3 promoter (Fig 2B) and, ultimately, with the reduced levels of ALDH1A3 mRNA, in the butein treated samples (Fig. 1E). RNAi-mediated downregulation of CEBP $\beta$ (Fig. 2F, left) strongly decreased both the ALDH1A3 endogenous mRNA (Fig. 2F, right) and the luciferase activity driven by the ALDH1A3 promoter (Fig. $2 \mathrm{G})$, thereby strictly mimicking the effect of butein and providing further support to the previous observations.

\section{STAT3 inhibition underlies the effect of butein on the DDIT3 levels}

DDIT3 is a target gene of STAT3 and its levels are upregulated in cells where binding of STAT3 to its promoter is diminished [28], implying active repression. Since we and others have shown that butein inhibits STAT3 [35, 37], we tested whether butein increased the levels of DDIT3 by inhibiting STAT3 activation.
First, we evaluated the status of the STAT3 pathway in purified ALDH ${ }^{\text {bright }}$ cells. Western blotting of whole cell lysates from both $\mathrm{ALDH}^{\text {bright }}$ and $\mathrm{ALDH}^{\text {low }}$ cells of three representative cell lines revealed strong enrichment for the pSTAT3(tyr705) signal (with slight changes in the levels of the total STAT3 protein) in the ALDH ${ }^{\text {bright }}$ cell fraction (Fig. 3A). Accordingly, quantitative PCR of 30 representative, literature selected STAT3 target genes [38] revealed that most of the targets exhibited higher levels in the ALDH ${ }^{\text {bright }}$ cells as opposed to the ALDH ${ }^{\text {low }}$ cells (suppl. Fig. 3). Butein treatment modulated the levels of most of the targets in both ALDH ${ }^{\text {bright }}$ and ALDH ${ }^{\text {low }}$ cells (Suppl. Fig. 3), and, to a much higher extent, the levels of a subset of those genes in the ALDH ${ }^{\text {bright }}$ cells, including DDIT3 (as compared to the ALDH ${ }^{\text {low }}$ cells)(Fig. 3B). Thus, the MPM ALDH ${ }^{\text {bright }}$ cells exhibited higher activation of the STAT3 pathway and responsivity to butein treatment.

We next investigated in detail the modulation of DDIT3 by butein. Since upregulation of DDIT3 by butein may result from increased promoter activity, we transfected HP-1 and MSTO-211H cells with a mCHERRY reporter driven by the minimal promoter of DDIT3 (-649/+136)[39](Fig. 3C). Butein treatment (18 $\mu \mathrm{M})$ strongly induced the promoter activity over time (as compared to vehicle treatment), as evidenced by the increase in the mCHERRY positive cells detected by fluorescence microscopy (Fig. 3C, p < 0.05). We next performed DNA affinity precipitation assays (DAPA) by using a biotinylated oligonucleotide containing the STAT3 binding site in the DDIT3 promoter. Western Blotting of the eluted material revealed that the binding of STAT3 to the promoter fragment in vitro was strongly reduced by butein treatment (18 $\mu \mathrm{M}$ for $8 \mathrm{hrs})$, as compared to vehicle treatment (Fig. 3D). Staining with a phosphoSTAT3 antibody (Tyr705) showed a strong reduction of the STAT3 phosphorylation in the butein-treated samples (Fig. 3D). Additionally, western blotting of the DAPA eluate with anti-NFkB(p65) antibodies revealed binding of NFkBp65 to the STAT3 oligonucleotide, which was strongly reduced upon butein-treatment (Fig. 3D). Altogheter, this correlated with the modulation of DDIT3 levels in the butein treated cells (Suppl. Fig. 2 and Fig. 2C2D). To support these in vitro observations, we performed CHIP experiments. First, we immunoprecipitated the chromatin from vehicle and butein treated MSTO-211H cells (18 $\mu \mathrm{M}$ for 20hrs) with antibodies specific for STAT3, phosphoSTAT3 (tyr705) and NFkB (p65) (Fig. 3E). Notably, the phospho-STAT3 antibody does not recognize un-phosphorylated STAT3. Quantitative PCR of the eluted chromatin with primers amplifying a region encompassing the STAT3 binding sequence used for the in vitro binding studies, revealed specific enrichment of the DDIT3 promoter fragment in the STAT3, pSTAT3 and NFkB immunoprecipitated chromatin (as compared to control IgG immunoprecipitation) and no amplification of a "off target" region was observed (Fig. 3E). Butein 
A

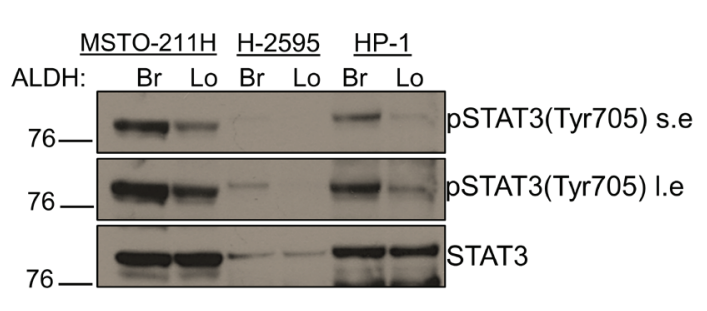

C
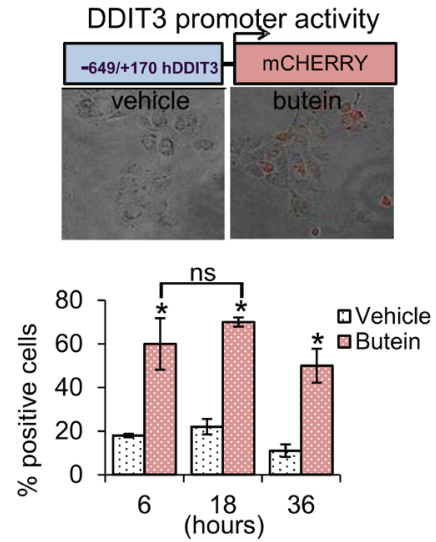

E

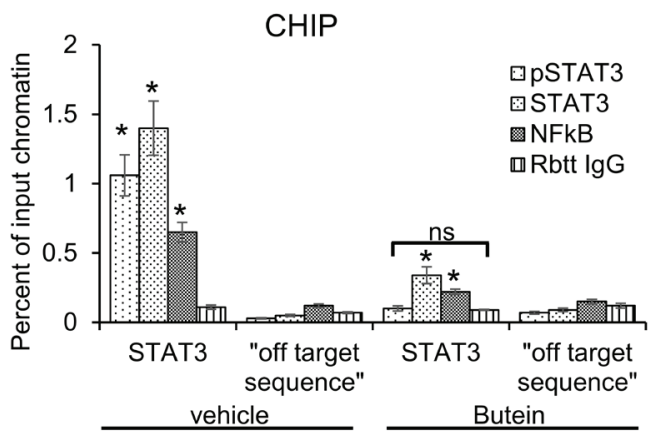

B

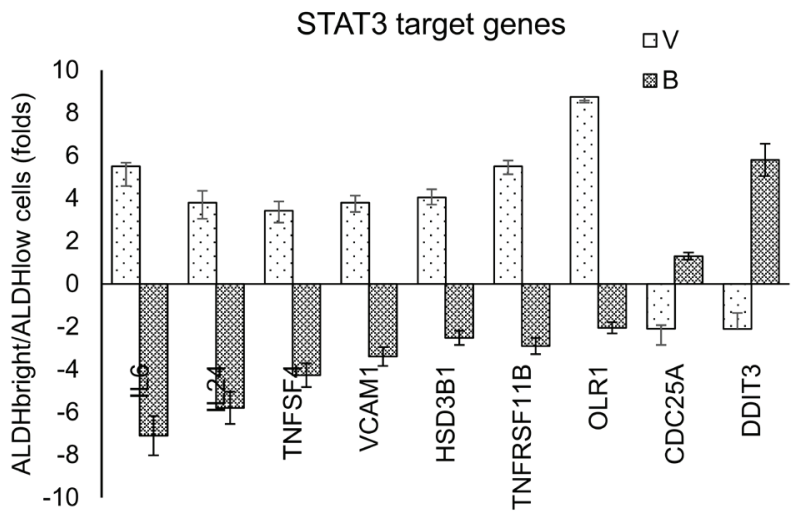

D

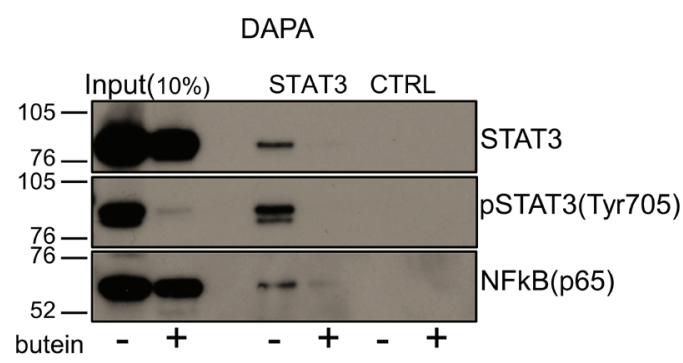

F
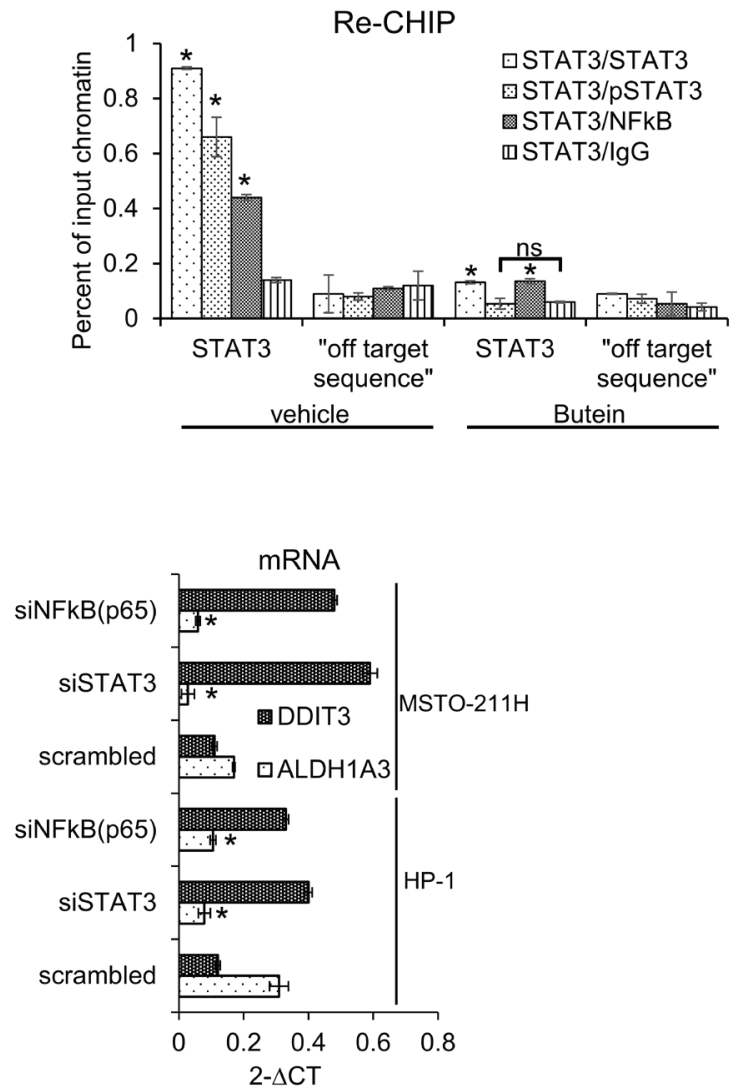
Figure 3: STAT3 inhibition underlies the effect of Butein on the DDIT3 levels. A. ALDHbright cells exhibit increased activation of the STAT3 pathway. Western blotting with specific anti-STAT3 and anti-phospho-STAT3(tyr705) antibodies of whole cell lysates from purified $\mathrm{ALDH}^{\text {bright }}$ and $\mathrm{ALDH}^{\text {low }}$ of three representative MPM cell lines (s.e: short exposure; l.e.: long exposure). B. mRNA levels of multiple STAT3 target genes in MSTO-211H ALDH ${ }^{\text {bright }}$ vs ALDH ${ }^{\text {low }}$ cells, upon treatment with vehicle or butein (18 $\left.\mu \mathrm{M}\right)$ for 24hrs. C. Upper. Combined bright field + fluorescent micrographs of MSTO-211H cells transfected with a mCherry reporter driven by the minimal DDIT3 promoter $(-649 /+170)$ and treated with butein $(18 \mu \mathrm{M})$ for 6 hrs. Scale bar: $20 \mu \mathrm{m}$. Lower. Percentage of mCherry positive cells in butein-treated cell cultures. A minimum of 8 fields (containing $\geq 30$ cells) was counted in duplicate experiments. D-F. Butein affects the binding of STAT3 and NFkB to the DDIT3 promoter. D. DNA Affinity Precipitation assay (DAPA) with a biotinylated oligonucleotide containing either a STAT3 binding site in the DDIT3 promoter (STAT3) or a control sequence (CTRL), respectively. Western blotting of the DAPA-eluted from nuclear extracts of MSTO-211H cells treated with vehicle and butein $(18 \mu \mathrm{M}, 6 \mathrm{hrs})$. Staining with antibodies against pSTAT3(Tyr705), STAT3 and NFkB(p65), respectively. E. In vivo occupancy of the DDIT3 promoter. Chromatin immunoprecipitation assays. Quantitative PCR revealing enrichment for the STAT3 containing DDIT3 promoter fragment in the eluate of STAT3, pSTAT3 and NFkB immunoprecipitates from vehicle or butein-treated MSTO-211H cells (18 $\mu \mathrm{M}, 20 \mathrm{hrs})$. A rabbit IgG and a "off target" DNA region in the same promoter were used to control for the specificity of immunoprecipitation and of the PCR reaction, respectively. F. RECHIP assays. Chromatin eluted from STAT3 immunoprecipitated material of vehicle- and butein -treated MSTO-211H cells (as from 3E) was re-immunoprecipitated with a rabbit IgG, STAT3, pSTAT3 and NFKB antibodies, respectively. Quantitative PCR revealed specific amplification of the DDIT3 promoter fragment suggesting the existence of a STAT3-NFKB complex. Duplicate experiments. G. RNAimediated downregulation of STAT3 and NFkB mimicked the effects of butein on DDIT3 and ALDH1A3 mRNA levels. Left. Western blotting with anti-STAT3 and anti-NFkB antibodies of whole cell lysates from MSTO-211H and HP-1 cells transfected with control (scrambled), STAT3 and NFkB targeting siRNA revealed effective downregulation of the protein levels. Actin used as a loading control. Right. Quantitative PCR revealed higher levels of DDIT3 mRNA and reduced levels of ALDH1A3 mRNA in the cells with reduced expression of STAT3 and NFkB. Values expressed as folds over controls (scrambled siRNAs). Statistics: $* p<0.05$; ns $=$ not significant: $(p$ $>0.05$ ). Student's t-test (comparing each sample to its control).

treatment significantly decreased the occupancy of the STAT3 binding site by all three factors $(P<0.05)$ (Fig. 3E). This suggest that a complex containing STAT3, pSTAT3 and NFkB binds to the STAT3 binding site of the DDIT3 promoter region in vivo.

In order to verify the existence of such a complex, we performed sequential chromatin immunoprecipitation experiments (re-CHIP) (Fig. 3F). After a first round of CHIP with anti STAT3 antibodies, we reimmunoprecipitated the eluted material with rabbit IgGs, STAT3, pSTAT3 and NFkB antibodies, respectively. Quantitative PCR revealed enrichment of the DDIT3 promoter fragment in the secondary immunoprecipitations (Fig.3F) demonstrating a physical association of STAT3 and NFkB. Additionally, the data suggested that the complex contained STAT3 in both its un-phosphorylated and phosphorylated (Tyr705) form (Fig. 3F). In order to assess the relevance of the single factors within the complex, we knocked-down STAT3 and NFkB (p65) in MSTO-211H and HP-1 cells by using RNAi. Western blotting with anti-STAT3 and anti-NFkB antibodies revealed effective downregulation of STAT3 and NFkB protein in the transfected cells (as compared to their control-scrambled RNA (Fig. 3G left panel). Quantitative PCR revealed higher levels of DDIT3 mRNA and reduced levels of ALDH1A3 mRNA in the cells with reduced expression of both STAT3 and NFkB (fig.3G, right panel), matching the observed binding of both factors the DDIT3 promoter in vivo (Fig. 3E-3F). Altogether, these data supported the reported ability of butein to interfere with the STAT3-NFkB interaction [35] and the reported indirect modulation of the DDIT3 levels by NFkB[40].

\section{Butein unlocks the constitutive, STAT3-dependent repression of DDIT3 mRNA in the ALDH ${ }^{\text {bright }}$ cells thereby affecting their tolerance to chemotherapy- induced stress}

Next, we focused on modulation of the DDIT3 mRNA levels in chemotherapy treated cells, with and without butein treatment. We found that purified ALDH ${ }^{\text {bright }}$ cells from all the MPM cell lines tested $(n=6)$ exhibited lower levels of DDIT3 mRNA than their ALDH $^{\text {low }}$ counterparts (Fig. 4A, heat map). Pemetrexed + cisplatin $(\mathrm{P}+\mathrm{C})$ treatment failed to upregulate the DDIT3 mRNA in the ALDH ${ }^{\text {bright }}$ cells (while readily doing so in the $\mathrm{ALDH}^{\text {low }}$ cells), in line with the relative resistance of the $\mathrm{ALDH}^{\text {bright }}$ cells to $\mathrm{P}+\mathrm{C}$ treatment (Fig. $4 \mathrm{~A}$, heat map). Importantly, butein treatment increased DDIT3 mRNA in both ALDH ${ }^{\text {bright }}$ and $\mathrm{ALDH}^{\text {low }}$ cells, raising the DDIT3 mRNA levels even in the $\mathrm{P}+\mathrm{C}$ treated $\mathrm{ALDH}^{\text {bright }}$ cells (Fig. $4 \mathrm{~A}$, heat map). The described trend in the mRNA levels was similarly observed when the DDIT3 protein levels were assessed in western blottings from representative $\mathrm{ALDH}^{\text {bright }}$ and $\mathrm{ALDH}^{\text {low }}$ MSTO-211H cells (Fig. 4B). In line with the previous observations, analysis of the clonogenicity of the $\mathrm{ALDH}^{\text {bright }}$ and $\mathrm{ALDH}^{\text {low }}$ cells treated as from Fig. 4A revealed that butein treatment potentiated the $\mathrm{P}+\mathrm{C}$ treatment in both cell subpopulations (Fig. 4C), suggesting that butein-mediated unlocking of the DDIT3 levels in the ALDH ${ }^{\text {bright }}$ cells was biologically relevant. Altogether, this correlated with the increased apoptotic response of the $\mathrm{ALDH}^{\text {bright }}$ cells when treated with $\mathrm{B}+\mathrm{P}+\mathrm{C}$ (Fig. 1G). Thus, butein treatment could reverse, in vitro, the resistance of ALDH ${ }^{\text {bright }}$ cells by counteracting the hyperactivation of the STAT3 pathway in the latter cell 
subpopulation.

\section{Butein treatment affects the ALDH ${ }^{\text {bright }}$ cell number in vivo and inhibits tumor growth}

In order to translate what we observed in vitro in an in vivo setting, we performed mouse xenograft experiments. Briefly, NOD-SCID mice were injected subcutaneously with $3^{*} 10^{\wedge} 6 \mathrm{MSTO}-211 \mathrm{H}$ cells and treated intraperitoneally with vehicle (V: 20\% DMSO/80\% corn oil), butein (B: $5 \mathrm{mpk})$, pemetrexed + cisplatin $(\mathrm{P}+\mathrm{C}$ : $45 \mathrm{mpk}+7 \mathrm{mpk}$, respectively) and butein + pemetrexed + cisplatin $(\mathrm{B}+\mathrm{P}+\mathrm{C} 5 \mathrm{mpk}+45 \mathrm{mpk}+7 \mathrm{mpk}$, respectively). Treatment (4 i.p injections at day 1, 3, 5 and 7) was started when the tumor $\geq 150 \mathrm{~mm} 3$ in volume (day 0 , $\mathrm{n}=6$ mice/group). Weighting of the excised tumors (at day 24) revealed a significant effect of butein, both when administered alone and, more strongly, when combined to $\mathrm{P}+\mathrm{C}$ (as compared to those excised from the vehicletreated mice) $(p<0.05)$ (Fig. 5A). Additionally, only $4 / 6$ tumors were detectable in the $\mathrm{B}+\mathrm{P}+\mathrm{C}$ treated mice at the time of excision (Fig. 5A, left and right panel). No statistically significant reduction in weight of the $\mathrm{P}+\mathrm{C}$ treated tumors as compared to the vehicle-treated tumors was observed (Fig. 5A, left panel). Butein treatment synergized with pemetrexed + cisplatin in reducing tumor weight, thus mirroring the chemosensitizing effects observed in vitro (Fig. 4C). We postulated that, as observed in vitro, the chemosensitizing effect observed in vivo should correlate with a change in the number of the

A

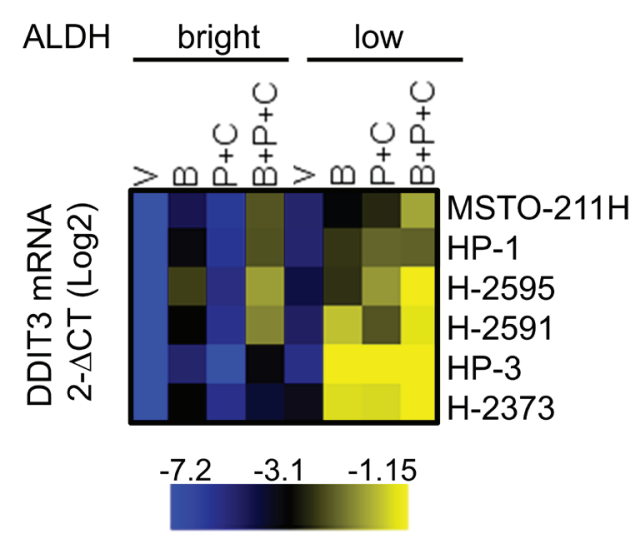

B
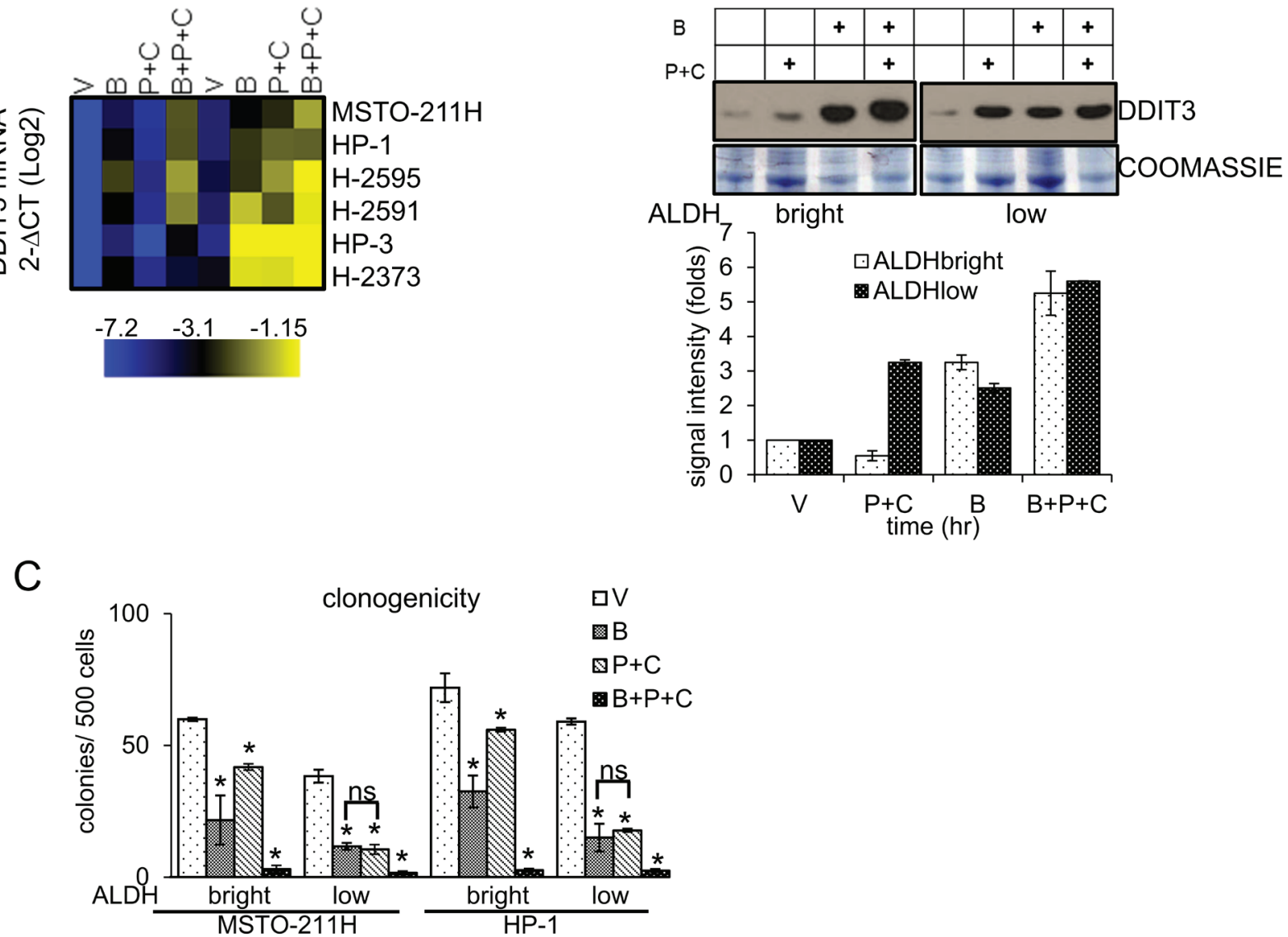

Figure 4: Butein unlocks the repression of DDIT3mRNA in the chemoresistant ALDH ${ }^{\text {bright }}$ cells. A. Heat map. DDIT3 mRNA levels in $\mathrm{ALDH}^{\text {bright }}$ and $\mathrm{ALDH}^{\text {low }}$ cells purified from the 6M PM cell lines and treated with vehicle (V: DMSO $0.05 \%$ ) and butein (B: $18 \mu \mathrm{M}$ ), alone or in combination with pemetrexed + cisplatin (P+C: $10 \mu \mathrm{M}+5 \mu \mathrm{M}$, respectively) for 16hrs. B. Upper. Western blotting with DDIT3 antibodies of whole cell lysates from purified ALDH ${ }^{\text {bright }}$ and ALDH ${ }^{\text {low }}$ MSTO-211H cells treated as in 4A. Coomassie staining used as a loading control. Lower. Histograms showing the changes in intensity signal of DDIT3 from duplicate experiments (normalized to two reference protein bands in the coomassie stained gel with Image J software). C. Clonogenic assays. Number of formed colonies from purified cell subpopulations of MSTO-211H and HP-1 cells treated with butein for 16hrs before seeding at clonal density. Histogram bars represent the mean \pm s.e.m of triplicate experiments. Statistics: ${ }^{*} p<0.05$; ns $=$ not significant: $(p>0.05)$. Student's t-test (comparing each sample to its control or, when indicated, to other samples within the same group). 
$\mathrm{ALDH}^{\text {bright }}$ cells within the butein treated tumor masses. FACS analysis of tumors disaggregated within one hour from harvesting revealed that the percentage of $\mathrm{ALDH}^{\text {bright }}$ cells was significantly reduced in the butein treated tumors $(p<0.05)$ (Fig. 5B). Within the same experimental setting, we observed no statistically significant change in the number of $\mathrm{ALDH}^{\text {bright }}$ cells within the pemetrexed + cisplatin treated tumors, while butein cotreatment caused the $\mathrm{ALDH}^{\text {bright }}$ cell number to drop significantly and dramatically upon $\mathrm{P}+\mathrm{C}$ treatment (as compared to the $\mathrm{P}+\mathrm{C}$ treated mice, $\mathrm{p}<0.05$, Fig. 5B).

\section{Butein-treated tumors exhibit inverse regulation of DDIT3 and ALDH1A3 mRNAs and lower levels of ALDH ${ }^{\text {bright }}$ cells}

Quantitative PCR of RNA extracted from pooled tumors ( $\mathrm{n}=4 /$ each group) showed downregulation of the ALDH1A3 mRNA and upregulation of DDIT3 mRNA in all the butein-treated tumors (Fig. 5C-D, respectively). $\mathrm{P}+\mathrm{C}$ treatment elicited an increase of DDIT3 mRNA as well (Fig. 5D), which however did not correlate with the ALDH ${ }^{\text {bright }}$ cell number (Fig. 5B) and with the ALDH1A3 mRNA levels (Fig. 5C). This apparent lack of correlation in the $\mathrm{P}+\mathrm{C}$ treated tumors was possibly due to the unsorted nature of the samples analyzed, thus reflecting the effect of the DNA damaging agents on the chemosensitive ALDH ${ }^{\text {low }}$ cell subpopulations, the predominant cell subpopulation in the excised tumors (Fig. 5B). To verify this possibility, we performed 3D clonogenic assays (a surrogate of tumor relapse) on the same cells and this revealed that the $\mathrm{B}+\mathrm{P}+\mathrm{C}$ treated tumors exhibited a large loss of sphere forming potential as compared to those derived from the $\mathrm{P}+\mathrm{C}$ treated mice which were mostly unaffected (as compared to the vehicle treated tumor masses, $\mathrm{p}<0.05$ ) (Fig. 5E) suggesting a reduced pool of chemoresistant cells in the butein-treated tumors due to targeting of the $\mathrm{ALDH}^{\text {bright }}$ chemoresistant cell subpopulations. In

B

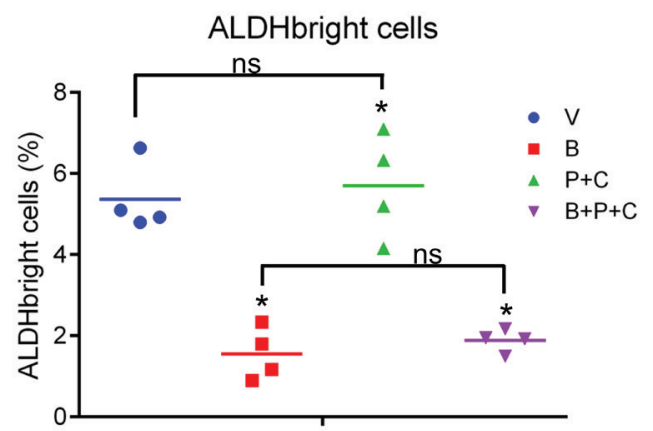

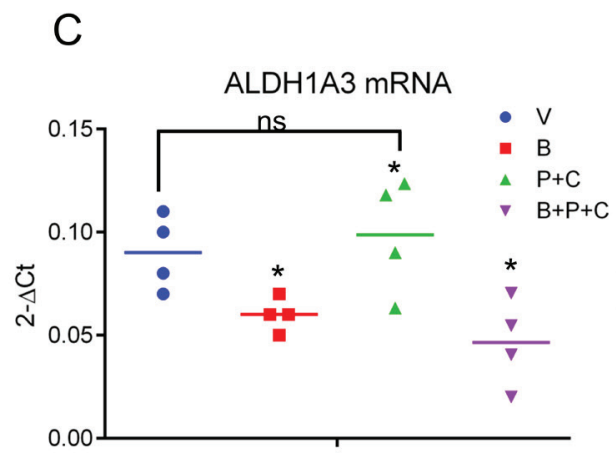
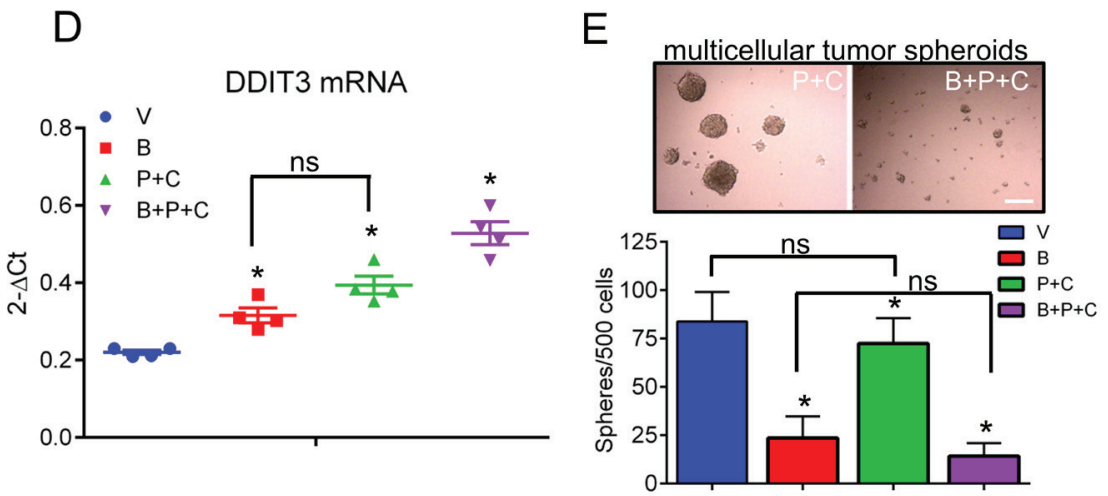

Figure 5: Butein treatment affects the ALDH ${ }^{\text {bright }}$ cell number in vivo and inhibits tumor growth. A. Average weight of tumors excised from NOD-SCID mice ( $\mathrm{n}=6$ /group) injected subcutaneously with $3^{*} 10^{\wedge} 6 \mathrm{MSTO}-211 \mathrm{H}$ cells and treated intraperitoneally with vehicle (V, $20 \% \mathrm{DMSO} / 80 \%$ corn oil), butein $(\mathrm{B}, 5 \mathrm{mpk})$, pemetrexed + cisplatin $(\mathrm{V}+\mathrm{P}+\mathrm{C}: 45 \mathrm{mpk}+7 \mathrm{mpk}$, respectively) and butein + pemetrexed + cisplatin $(\mathrm{B}+\mathrm{P}+\mathrm{C} 5 \mathrm{mpk}+45 \mathrm{mpk}+7 \mathrm{mpk}$, respectively) after tumor formation. Duplicate experiments. Inset. Representative micrographs of tumors excised from $\mathrm{P}+\mathrm{C}$ and $\mathrm{B}+\mathrm{P}+\mathrm{C}$ treated mice, respectively, at day 24 p.i. Scale bar: 0.5 inches. B. FACS plots show the average percentage of $\mathrm{ALDH}^{\text {bright }}$ cells from freshly excised and disaggregated tumors. $\mathbf{C}$-D. Butein-treated tumors exhibit inverse regulation of DDIT3 and ALDH1A3 mRNAs. The levels of DDIT3 and ALDH1A3 mRNAs were assessed by quantitative PCR in freshly excised tumors. Asterisks indicate outliers. E. Upper panel. Representative micrographs of 3D clonogenic assays performed with cells derived from the disaggregated tumors of mice treated with $\mathrm{V}+\mathrm{P}+\mathrm{C}$ or $\mathrm{B}+\mathrm{P}+\mathrm{C}$. Scale bar: $100 \mu \mathrm{m}$. Lower panel. Average number of 3D spheroids formed from the disaggregated tumors. Duplicate experiments. Histogram bars represent the mean \pm s.e.m. Statistics: $* p<0.05$; $\mathrm{ns}=$ not significant: $(p>0.05)$. One-way analysis of variance with Tukey's post hoc corrections-comparing the mean of each group with the mean of every other group. 
summary, butein can increase the DDIT3 mRNA levels in the ALDH ${ }^{\text {bright }}$ cells and this may rescue the sensitivity of such a cell subpopulation to the chemotherapy-induced stress both in vitro and in vivo (Fig. 6).

\section{DISCUSSION}

In this work, by exploiting Malignant Pleural Mesothelioma as an experimental model of tumor chemoresistance $[4,41]$, we demonstrated that a specific ALDH isoform, namely ALDH1A3, is enriched in chemoresistant mesothelioma cell subpopulations purified from multiple sources. This observation echoes what others have observed in breast, melanoma, non-small cell lung-cancers and mesenchymal-type glioma [14, 18, $19,30,42]$. Here we can add that expression of ALDH1A3 impinges on the tolerance to stress-induced chemotherapy in vitro and in vivo. In line with this function, we show that this process is modulated by factors known to play a role in cancer chemoresistance [34, 43-47]. In facts, among the factors shown here to modulate ALDH1A3 expression, C/ EBP $\beta$ and STAT3 have already emerged as prognostically relevant modulators of the glioma mesenchymal phenotype $[31,48]$ and NFkB was shown to be constitutively active in a number of tumors [32],including MPM, where its constitutive activity may results from the asbestos-induced chronical inflammation [49]. Additionally, DDIT3 was identified in a TCGA worst-prognosis signature (TWPS) comprising 884 genes differentially expressed in worst versus best prognosis gliomas [31] and low DDIT3 levels may be prognostically relevant for MPM [50]. Notably, low DDIT3 levels are a requirement for RAS-mediated cell transformation [51].

It is very likely that the function of the STAT3/ NFkB axis here described does not influence only the ALDH1A3 promoter and may involve modulation of additional CEBP $\beta$-dependent promoters. Additionally, cells endowed with high cytoplasmic levels of DDIT3 exhibited modulation of complex and novel transcriptional targets encompassing both activation and repression functions, when challenged with stress stimuli [52]. Thus, the survival of the ALDH ${ }^{\text {bright }}$ cells may rely on additional pathways perturbed by the reciprocal modulation of DDIT3/CEBP $\beta$ activity, not addressed here. While this can be a limitation of the present work, it does not detract from the central role played by ALDH1A3 in contributing resistance of the $\mathrm{ALDH}^{\text {bright }}$ cells to stress. In line with this, the fact that knocking down of ALDH1A3 did not increase the effect of butein strongly suggests that modulation of ALDH1A3 activity is a main target mechanism of this compound.

Here we do not address how the ALDH1A3 expression contributes stress tolerance to the $\mathrm{ALDH}^{\text {bright }}$ cells. The contribution of ALDH1A3 to survival is probably complex and results from multiple mechanisms. For example, enriched expression for ALDH1A3 was shown to confer specific metabolic features to glioma "stem-like" cells [19]. In line with our observations

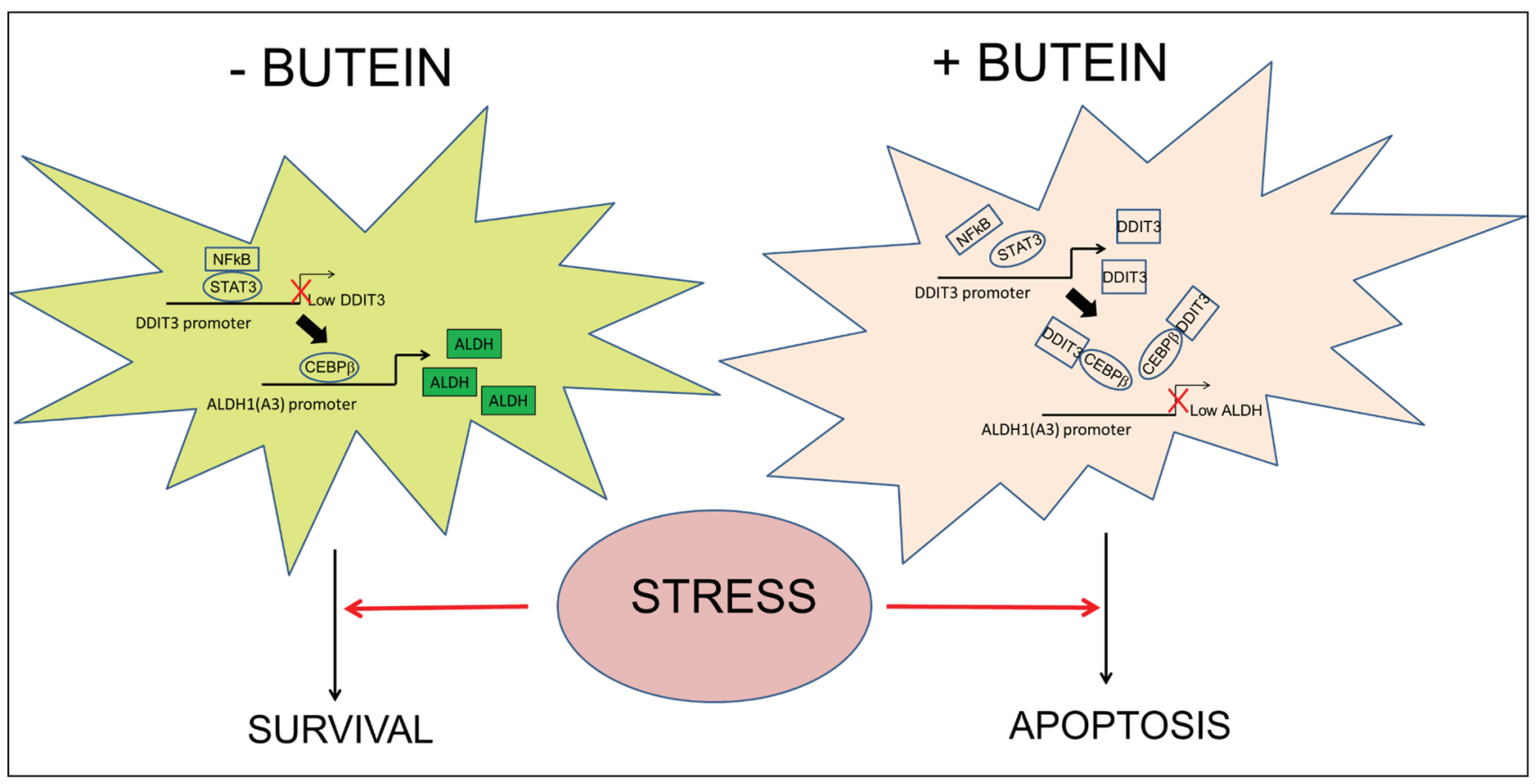

Figure 6: Proposed working model. The ALDH ${ }^{\text {bright }}$ cells exhibit constitutive activation of the STAT3 pathway which triggers downregulation of DDIT3 mRNA levels both at steady state and upon pemetrexed+cisplatin treatment. Interference with STAT3NFkB function unlocks expression of DDIT3 in the ALDH ${ }^{\text {bright }}$ cells and this reduces the occupancy of ALDH1A3 promoter by CEBP $\beta$ thereby lowering ALDH1A3 expression and the intracellular ALDH activity and strongly affecting the survival of the ALDH ${ }^{\text {bright }}$ cells to chemotherapy-induced stress. 
showing that ALDH1A3 is STAT3 target, it is intriguing to observe how the metabolic phenotype of the ALDH1A3 expressing glioma cells, consisting of aerobic glycolysis, is similar to that of cells expressing a transforming version of the STAT3 protein with increased nuclear retention and transcriptional activity $[19,53]$. ALDH1A3 is also very important for the production of retinoic acid (RA) $[54,55]$. We may speculate that the ALDH ${ }^{\text {bright }}$ cells (enriched for ALDH1A3 expression/activity) may indeed produce retinoic acid (RA) metabolites, the latter acting as paracrine signaling molecules. RA may signal to adjacent cells and confer protumorigenic properties. Relevant to this, Marcato and Lee's groups have demonstrated that ALDH1A3-mediated modulation of RA-target genes contributes in vivo protumorigenic properties including the transcription of the MUC4 oncogene [20], to MDAMB-231 breast cancer cells. Last but not least, our observations suggest that butein-mediated downregulation of ALDH1A3 is pro-apoptotic and this effect is much increased in presence of pemetrexed + cisplatin mediated DNA damage. Interestingly, involvement in the DNA damage response was recently identified as a function of ALDH1A1 in breast, prostate and ovary cancer cells $[12,56,57]$. The downregulation of ALDH1A3 may thus amplify a DNA damage response, consistent with the chemosensitizing effects observed in vivo.

On a wider perspective, low DDIT3 levels in the $\mathrm{ALDH}^{\text {bright }}$ cells may promote unperturbed $\mathrm{CEBP} \beta$ activity during stress. CEBP $\beta$ is a modulator of the mesenchymal phenotype and interference with CEBP $\beta$ function (in absence of adipogenic or chondrocyte commitment stimuli), is known to negatively affect the undifferentiated state of mesenchymal precursors[58]. Relevant to this, we have shown that the ALDH ${ }^{\text {bright }}$ cells exhibit mesenchymal properties such as expression of mesenchymal markers and hypermigratory features [4] and ALDH activators were shown to increase expression of mesenchymal markers and multipotency of salivary gland precursors [59]. Thus, we may speculate that keeping DDIT3 levels low in stress conditions would allow the ALDH ${ }^{\text {bright }}$ cells to survive, to transmit protumorigenic stimuli to adjacent cells and to maintain a specific, possibly differentiation related, metabolic cell identity.

For the in vivo studies, we have exploited butein, already known to us for counteracting chemoresistance of MPM cells in vivo and in vitro [35]. To note, we show here that the 3D clonogenicity of the cells derived from buteintreated excised tumors is strongly reduced. This suggests the possibility that butein may exhaust the chemoresistant cell pool within treated tumors and thus may prevent or strongly delay tumor relapse. This has some translational relevance especially if we consider that butein was shown to not affect normal, untransformed cell lines and to not shorten survival of non-tumor bearing mice [35]. Last, our observations might likely be of interest for other neoplastic diseases characterized by STAT3-NFkB activation and chemoresistance.

\section{MATERIALS AND METHODS}

\section{Cell lines and culture conditions}

The human MPM cell lines MSTO-211H, H-28, H-2052 were from ATCC (Manassas, VA, USA). H-2591, H-2818, H-2595, H-2373, H-2461, HP-1, H-2596 were obtained as described elsewhere [60]. All the cell lines were Mycoplasma free and used at passages 2-6 from thawing. Cells were cultured as monolayers at $37^{\circ} \mathrm{C}$ and $5 \% \mathrm{CO}_{2}$ in DMEM/F12+GLUTAMAX supplemented with $10 \%$ non-heat inactivated FBS (fetal bovine serum) (Life Technologies, Gran Island, NY USA). For drug treatments, cells were exposed for the indicated length of time to butein, cisplatin and pemetrexed. Afterthat growth medium was changed with a drug free medium and cells allowed to growth for the additional time indicated in each legend.

\section{Reagents}

Pemetrexed, cisplatin and butein (Selleckchem, Texas, USA) were dissolved according to the manufacturer's instructions.

\section{Retroviral transduction, promoter reporter and luciferase assay}

The shRNA containing vectors targeting ALDH1A3, ALDH1A1, ALDH2 and the scrambled non targeting control vector were previously described [14]. The viral vectors were transfected into $293 \mathrm{~T}$ packaging cells using Lipofectamine 2000 (Invitrogen, Life Technologies, Grand Island, NY USA) according to the manufacturer's instructions. 48hours later the viruscontaining supernatants were filtered $(0.45 \mu \mathrm{M})$ and used to infect the recipient MPM cell lines. Where possible, the infected cells were selected by puromycin $(1 \mu \mathrm{g} / \mathrm{ml}$ every $48 \mathrm{~h}$ for 1 week). CHOP promoter/pmCherry-1(\#36035, Addgene, Cambridge, MA) was transfected into MPM cells using Lipofectamine 2000 (Life Technologies) according to the manufacturer's instructions. To evaluate the ALDH1A3 promoter transcriptional activity, we used a Luciferase reporter construct (SwitchGear, Active Motif Carlsbad, CA), transfected into cells, according to the manufacturer's instructions. Luciferase activity was measured using the Light Switch Assay reagent (Active Motif, Carlsbad, CA, USA.) 


\section{RNA interference}

STAT3, CEBP $\beta$, NFkB (p65-RelA) targeting siRNA (TRILENCER-27 siRNAs) were from Origene Technologies (Rockwille, MD, USA) and were transfected with siTRAN siRNA transfection reagent following manufacturer's instructions. Cells were harvested at $24 \mathrm{hrs}$ (for RNA extraction) or 48hrs (for protein studies)

\section{ALDH activity assay and cell sorting}

ALDEFLUOR kit (Stem Cell Technologies, Vancouver, Canada) was used according to the manufacturer's instructions. ALDH-positive cells were defined as the cells that displayed greater fluorescence compared with a control staining reaction containing the ALDH inhibitor, DEAB (diethylaminobenzaldehyde), upon addition of the synthetic ALDH substrate BAAA. Cell sorting was performed using a FACSAria flow cytometer (Becton Dickinson, Mississauga, Canada). Dead cells positive to SYTOX Red Dead Cell Stain (Life Technologies, Grand Island, NY) were excluded.

\section{Colony forming assay (CFA)}

MPM cell lines were grown to $70 \%$ confluence and pulse- treated with the indicated drugs or transfected as indicated. $16 \mathrm{hrs}$ later, cells were detached and seeded at 500-1500 cells/well into 6-well dishes in drug-free media ( $2 \mathrm{ml}$ medium /well). Fresh medium (25\%) was added every three days. Colonies were stained with crystal violet (SIGMA) and colonies ( $>50$ cells) counted after 7- 14 days (this wide range reflects differences in the proliferation of the colonies for each MPM cell line). For 3D clonogenic assays, the cells were plated in anchorage independent and serum free conditions in DMEM-F12/1:1 + Glutamax supplemented with BSA and EGF(10ng/ml) and FGF2(10 $\mathrm{ng} / \mathrm{ml}$ ) (Life Technologies) as previously described[61].

\section{RNA extraction and cDNA synthesis and gene expression}

Total RNA was extracted using the RNAeasy minikit (QIAGEN).The first-strand cDNA was synthesized with the High Capacity RNA-to cDNA kit, (Applied Biosystems). Gene expression was measured by real-time PCR using the SYBRGreen dye (Applied Biosytems) on a Step One instrument (Applied Biosytems). Specific primers for ALDH isoforms were described previously[14]. DDIT3 primers were: forward: -GGAAACAGAGTGGTCATTCCC; reverse: CTGCTTGAGCCG-TTCATTCTC. PPIA and HPRT were used as endogenous control and were described previously[62].

\section{Immunofluorescence microscopy}

Briefly, the cells were fixed and permeabilized in paraformaldehyde/methanol, non-specific binding blocked with PBS containing 1\% BSA for 1 hour at room temperature and labeled with a mouse monoclonal anti-DDIT3 (Abcam, Cambridge, UK). The secondary antibody was an anti-mouse IgG Texas red (Abcam). Cell nuclei were visualized by 4',6-diamidino-2-phenylindole (DAPI) staining. For counting the mCHERRY positive cells, a minimum of 8 fields (containing $\geq 40$ cells) was counted in duplicate experiments. Quantification of fluorescence was performed in Image $₫$ and the number of cells with a mean fluorescent intensity (MFI) above the threshold (set on untransfected cells) was reported were indicated.

\section{Apoptosis detection}

Dead cells were measured by FACS analysis after SYTOX Dead Cell Stain-labeling (Life Technologies, Gran Island, NY USA), according to the manufacturer's instructions. The Human Apoptosis Antibody Array (R\&D, Minneapolis, MN, USA) was used to simultaneously detect the relative expression of 35 apoptosis-related proteins.

\section{Cell lysis, immunoprecipitation and western blotting}

Briefly, cells were lysed in cell lysis buffer $(50 \mathrm{mM}$ Tris- $\mathrm{HCl}(\mathrm{pH}$ 8), 0.5\% IGEPAL AC-630, $150 \mathrm{mM}$ $\mathrm{NaCl}, 1 \mathrm{mM}$ EDTA, and $10 \%$ glycerol, supplemented with protease and phosphatase inhibitors, to generate total cell extracts. For the immunoprecipitation studies the following antibodies were used: mouse antiCHOP (Abcam, Cambridge, UK), mouse anti-STAT3 (Santa Cruz Biotechnology, CA, USA), rabbit antiphosphoSTAT3(tyr705)(Cell Signaling), mouse-antiCEPB $\beta$, rabbit-anti-NFKB (Santa Cruz Biotechnology). For the western blotting: rabbit anti- $\mathrm{CHOP}$, rabbit anti-CEPB $\beta$ (Cell Signaling, Danvers, MA, USA), goat anti-ALDH1A3 (Santa Cruz Biotechnology), rabbit anti-p-STAT3 (Cell Signaling), rabbit anti-STAT3 (Cell Signaling), mouse anti-ALDH2 (Abnova, Walnut, CA, USA), mouse anti-ALDH1 (this antibody mainly recognizes ALDH1A1) (BD Biosciences, NJ, USA), rabbit anti-ALDH1A3 (Abgent, San Diego, CA, USA) were used. Rabbit anti-ACTIN staining (Santa Cruz Biotechnology) or mouse anti-GAPDH (Pierce, Rockford, IL, USA) were used as a loading control. For the chemiluminescent detection of the secondary antibodies, a Western Bright ECL HRP substrate (ADVANSTA, Menlo Park, CA,) was used. Please note that for the western 
blotting of lysates from purified cell subpopulations, a supersensitive detection reagent was used (WesternBright Sirius HRP substrate) given the low amount of material available. Densitometry was performed on scanned western blotting images using the Image $\mathbb{R}$ software. Relative intensity for each protein band was reported after normalization to its loading control, where indicated in the figure legend.

\section{DNA affinity precipitation assay}

Briefly, cells were collected in cold PBS/ $2 \mathrm{mM}$ EDTA and lysed in DAPA lysis buffer $(50 \mathrm{mM}$ Tris- $\mathrm{HCl}$ $\mathrm{pH}$ 8, 0.5\% IGEPAL-AC-630, $100 \mathrm{mM} \mathrm{NaCl,} 1 \mathrm{mM}$ EDTA, $1 \mathrm{mM} \mathrm{MgCl}_{2}$ and $10 \%$ glycerol), supplemented with protease and phosphatase inhibitors to generate total cell extracts. Cell extracts were diluted three times in IP buffer (20 mM Tris- $\mathrm{HCl} \mathrm{pH} 8,10 \mathrm{mM} \mathrm{NaCl}, 0.5$ $\mathrm{mM}$ EDTA, $0.5 \mathrm{mM} \mathrm{MgCl}_{2}$ and $10 \%$ glycerol) with protease and phosphatase inhibitors and incubated with the 5'-biotinylated DNA oligonucleotides $(2.5 \mu \mathrm{g} / 0.5 \mathrm{mg}$ cell lysate) complexed to streptavidin-agarose magnetic beads in IP buffer at $4^{\circ} \mathrm{C}$ for $2 \mathrm{~h}$. The oligo-beads complex was washed 5 times with washing buffer $(10 \mathrm{mM}$ Tris- $\mathrm{HCl}$ $\mathrm{pH} 8,0.5 \%$ IGEPAL-AC-630, $175 \mathrm{mM} \mathrm{NaCl}, 0.25 \mathrm{mM}$ $\mathrm{MgCl}_{2}$ and $5 \%$ glycerol) and eluted with Laemmli buffer at $65 \mathrm{C}$ for 5 minutes. The sequence of the oligonucleotide isbiotin-5-TCTTCATTTCCAGGAGGTGAAA-3.

As a control $10 \mu \mathrm{g}$ of competitor non-biotin-labeled oligonucleotide were preincubated with the nuclear extract before adding the biotin-labeled one as described above.

\section{Chromatin immunoprecipitation (CHIP)}

SimpleChIP® Enzymatic Chromatin IP Kit Magnetic Beads(Cell Signaling) was used according to the manufacturer's instructions except that the supernatant of the digestion reaction (Micrococcal Nuclease) was not discarded and used for the immunoprecipitation cocktail Briefly, $150 \mu \mathrm{g}$ of crosslinked/sonicated chromatin was incubated with antibody overnight at $4^{\circ} \mathrm{C}$. Antibodies used were as follows: mouse anti-STAT3 and rabbit antiCEPB $\beta$ (Santa Cruz Biotechnology, Santa Cruz, CA); anti-pSTAT3(Tyr705), rabbit-anti-NFkB (Cell Signaling) and the negative control Normal Rabbit IgG samples (Cell Signaling) . CHIP Grade Protein G Magnetic Beads were added to the samples after BSA blocking and incubated for $4 \mathrm{~h}$ at $4^{\circ} \mathrm{C}$ with rotation. After several washes (low salt and high salt), complexes were eluted and DNA crosslinking reversed. DNA was purified using Spin Columns. Quantitative PCR for CHIP analysis was performed as indicated before, by using SYBR green (Applied Biosystems). Fold-change enrichment (relative to a $2 \%$ input chromatin) was calculated using the formula: Percent Input $=2 \% \times 2^{\wedge}(\mathrm{C}[\mathrm{T}] 2 \%$ Input Sample $-\mathrm{C}[\mathrm{T}]$ IP Sample).
The specific primers for the CEBP $\beta$ binding site in the ALDH1A3 promoter (chr15: 101419959-101419973) and for the STAT3 binding site in the DDIT3 promoter (chr12: 57911053-57911074) and the "off target" controls (Epitect CHIP primers) were commercially available (Qiagen, Valencia, CA).

\section{ALDH1A3 and DDIT3 promoter analysis}

Promoter analysis was performed using the MatInspector software (http://www.genomatix.de) and $\mathrm{MATCH}^{\mathrm{TM}}$, BIOBASE. A sequence $2 \mathrm{~kb}$ upstream and $2 \mathrm{~kb}$ downstream from the transcription start site was analyzed for the presence of putative binding sites for each TF.

\section{Animal studies}

All animal work was performed in accordance with NYU guidelines and upon IACUC approval. Suspensions of $3 \times 10^{6} \mathrm{MSTO}-211 \mathrm{H}$ cells were injected subcutaneously. in PBS1X into 5-weeks-old male NOD/ SCID mice (Charles River, Italy). Body weight and clinical signs of the mice were determined every 3 days. When tumor volume $\geq 150 \mathrm{~mm}^{3}$, mice were randomized and treated intraperitoneally with vehicle (V, 20\% DMSO/80\% corn oil), butein (B, 5mpk), pemetrexed + cisplatin $(\mathrm{P}+\mathrm{C}: 45 \mathrm{mpk}+7 \mathrm{mpk}$, respectively) and butein + pemetrexed + cisplatin $(\mathrm{B}+\mathrm{P}+\mathrm{C} 5 \mathrm{mpk}+45 \mathrm{mpk}+7 \mathrm{mpk}$, respectively). Treatment (4 i.p injections at day 1,3,5,7) started when the tumor $\geq 150 \mathrm{~mm} 3$ in volume (day $0, n=6$ mice/group).

\section{Statistical analysis}

One-way analysis of variance with Tukey's post hoc corrections-comparing the mean of each group with the mean of every other group or Student's $t$-test (comparing each sample to its control or, when indicated, to other samples within the same group). Statistical significance was defined as $p<0.05$ where indicated. Except when indicated in the legend, all the data were from at least 3 biological replicate experiments. The GraphPad software was used for all the statistics.

\section{ACKNOWLEDGMENTS}

This study is supported by NYU Cancer Institute Cancer Center Developmental Project Program (P30CA016087). We are very grateful to the NYU Flow Cytometry and Cell Sorting Center for their help and assistance with FACS sorting. We thankfully acknowledge Dr. Michele Carbone and Dr. Haining Yang (Hawaii Cancer Center) for their helpful suggestions and comments. 


\section{CONFLICTS OF INTEREST}

The authors declare no conflict of interest.

\section{REFERENCES}

1. Carbone M, Ly BH, Dodson RF, Pagano I, Morris PT, Dogan UA, Gazdar AF, Pass HI and Yang H. Malignant mesothelioma: facts, myths, and hypotheses. Journal of cellular physiology. 2012; 227:44-58.

2. Hazarika M, White RM, Jr., Booth BP, Wang YC, Ham DY, Liang CY, Rahman A, Gobburu JV, Li N, Sridhara R, Morse DE, Lostritto R, Garvey P, Johnson JR and Pazdur R. Pemetrexed in malignant pleural mesothelioma. Clinical cancer research : an official journal of the American Association for Cancer Research. 2005; 11:982-992.

3. Pasello G, Ceresoli GL and Favaretto A. An overview of neoadjuvant chemotherapy in the multimodality treatment of malignant pleural mesothelioma. Cancer treatment reviews. 2013; 39:10-17.

4. Canino C, Mori F, Cambria A, Diamantini A, Germoni S, Alessandrini G, Borsellino G, Galati R, Battistini L, Blandino R, Facciolo F, Citro G, Strano S, Muti P, Blandino $G$ and Cioce M. SASP mediates chemoresistance and tumor-initiating-activity of mesothelioma cells. Oncogene. 2012; 31:3148-3163.

5. Liu J, Xiao Z, Wong SK, Tin VP, Ho KY, Wang J, Sham $\mathrm{MH}$ and Wong MP. Lung cancer tumorigenicity and drug resistance are maintained through ALDH(hi)CD44(hi) tumor initiating cells. Oncotarget. 2013; 4:1698-1711.

6. Pors K and Moreb JS. Aldehyde dehydrogenases in cancer: an opportunity for biomarker and drug development? Drug discovery today. 2014.

7. Moreb JS, Ucar D, Han S, Amory JK, Goldstein AS, Ostmark B and Chang LJ. The enzymatic activity of human aldehyde dehydrogenases 1A2 and 2 (ALDH1A2 and ALDH2) is detected by Aldefluor, inhibited by diethylaminobenzaldehyde and has significant effects on cell proliferation and drug resistance. Chemico-biological interactions. 2012; 195:52-60.

8. Moreb JS, Zucali JR, Ostmark B and Benson NA. Heterogeneity of aldehyde dehydrogenase expression in lung cancer cell lines is revealed by Aldefluor flow cytometry-based assay. Cytometry Part B, Clinical cytometry. 2007; 72:281-289.

9. Marchitti SA, Brocker C, Stagos D and Vasiliou V. Non-P450 aldehyde oxidizing enzymes: the aldehyde dehydrogenase superfamily. Expert opinion on drug metabolism \& toxicology. 2008; 4:697-720.

10. Hellstrom $\mathrm{E}$ and Tottmar O. Effects of aldehyde dehydrogenase inhibitors on enzymes involved in the metabolism of biogenic aldehydes in rat liver and brain. Biochemical pharmacology. 1982; 31:3899-3905.

11. Moreb JS, Maccow C, Schweder M and Hecomovich
J. Expression of antisense RNA to aldehyde dehydrogenase class-1 sensitizes tumor cells to 4-hydroperoxycyclophosphamide in vitro. The Journal of pharmacology and experimental therapeutics. 2000; 293:390-396.

12. Sladek NE, Kollander R, Sreerama L and Kiang DT. Cellular levels of aldehyde dehydrogenases (ALDH1A1 and ALDH3A1) as predictors of therapeutic responses to cyclophosphamide-based chemotherapy of breast cancer: a retrospective study. Rational individualization of oxazaphosphorine-based cancer chemotherapeutic regimens. Cancer chemotherapy and pharmacology. 2002; 49:309-321.

13. Jia J, Parikh H, Xiao W, Hoskins JW, Pflicke H, Liu X, Collins I, Zhou W, Wang Z, Powell J, Thorgeirsson SS, Rudloff U, Petersen GM and Amundadottir LT. An integrated transcriptome and epigenome analysis identifies a novel candidate gene for pancreatic cancer. BMC medical genomics. 2013; 6:33.

14. Marcato P, Dean CA, Giacomantonio CA and Lee PW. Aldehyde dehydrogenase: its role as a cancer stem cell marker comes down to the specific isoform. Cell cycle. $2011 ; 10: 1378-1384$

15. Marcato P, Dean CA, Pan D, Araslanova R, Gillis M, Joshi M, Helyer L, Pan L, Leidal A, Gujar S, Giacomantonio CA and Lee PW. Aldehyde dehydrogenase activity of breast cancer stem cells is primarily due to isoform ALDH1A3 and its expression is predictive of metastasis. Stem cells. 2011; 29:32-45.

16. Yang ZL, Yang L, Zou Q, Yuan Y, Li J, Liang L, Zeng $\mathrm{G}$ and Chen S. Positive ALDH1A3 and negative GPX3 expressions are biomarkers for poor prognosis of gallbladder cancer. Disease markers. 2013; 35:163-172.

17. Zhang W, Yan W, You G, Bao Z, Wang Y, Liu Y, You $\mathrm{Y}$ and Jiang T. Genome-wide DNA methylation profiling identifies ALDH1A3 promoter methylation as a prognostic predictor in G-CIMP- primary glioblastoma. Cancer letters. 2013; 328:120-125.

18. Luo Y, Dallaglio K, Chen Y, Robinson WA, Robinson SE, McCarter MD, Wang J, Gonzalez R, Thompson DC, Norris DA, Roop DR, Vasiliou V and Fujita M. ALDH1A isozymes are markers of human melanoma stem cells and potential therapeutic targets. Stem cells. 2012; 30:21002113.

19. Mao P, Joshi K, Li J, Kim SH, Li P, Santana-Santos L, Luthra S, Chandran UR, Benos PV, Smith L, Wang M, Hu B, Cheng SY, Sobol RW and Nakano I. Mesenchymal glioma stem cells are maintained by activated glycolytic metabolism involving aldehyde dehydrogenase $1 \mathrm{~A} 3$. Proceedings of the National Academy of Sciences of the United States of America. 2013; 110:8644-8649.

20. Marcato P, Dean CA, Liu RZ, Coyle KM, Bydoun M, Wallace M, Clements D, Turner C, Mathenge EG, Gujar SA, Giacomantonio CA, Mackey JR, Godbout R and Lee PW. Aldehyde dehydrogenase 1A3 influences breast 
cancer progression via differential retinoic acid signaling. Molecular oncology. 2014.

21. Alam M, Ahmad R, Rajabi H, Kharbanda A and Kufe D. MUC1-C oncoprotein activates ERK-->C/EBPbeta signaling and induction of aldehyde dehydrogenase 1A1 in breast cancer cells. The Journal of biological chemistry. 2013; 288:30892-30903.

22. Elizondo G, Medina-Diaz IM, Cruz R, Gonzalez FJ and Vega L. Retinoic acid modulates retinaldehyde dehydrogenase 1 gene expression through the induction of GADD153-C/EBPbeta interaction. Biochemical pharmacology. 2009; 77:248-257.

23. Mamat S, Ikeda J, Tian T, Wang Y, Luo W, Aozasa K and Morii E. Transcriptional Regulation of Aldehyde Dehydrogenase 1A1 Gene by Alternative Spliced Forms of Nuclear Factor Y in Tumorigenic Population of Endometrial Adenocarcinoma. Genes \& cancer. 2011; 2:979-984.

24. Yanagawa Y, Chen JC, Hsu LC and Yoshida A. The transcriptional regulation of human aldehyde dehydrogenase I gene. The structural and functional analysis of the promoter. The Journal of biological chemistry. 1995; 270:17521-17527.

25. Ron D and Habener JF. CHOP, a novel developmentally regulated nuclear protein that dimerizes with transcription factors $\mathrm{C} / \mathrm{EBP}$ and LAP and functions as a dominantnegative inhibitor of gene transcription. Genes \& development. 1992; 6:439-453.

26. Gately DP, Jones JA, Christen R, Barton RM, Los G and Howell SB. Induction of the growth arrest and DNA damage-inducible gene GADD153 by cisplatin in vitro and in vivo. British journal of cancer. 1994; 70:1102-1106.

27. Jackman J, Alamo I, Jr. and Fornace AJ, Jr. Genotoxic stress confers preferential and coordinate messenger RNA stability on the five gadd genes. Cancer research. 1994; 54:5656-5662.

28. Timofeeva OA, Tarasova NI, Zhang X, Chasovskikh S, Cheema AK, Wang H, Brown ML and Dritschilo A. STAT3 suppresses transcription of proapoptotic genes in cancer cells with the involvement of its N-terminal domain. Proceedings of the National Academy of Sciences of the United States of America. 2013; 110:1267-1272.

29. Zhang JX, Zhang J, Yan W, Wang YY, Han L, Yue X, Liu N, You YP, Jiang T, Pu PY and Kang CS. Unique genomewide map of TCF4 and STAT3 targets using ChIP-seq reveals their association with new molecular subtypes of glioblastoma. Neuro-oncology. 2013; 15:279-289.

30. Shao C, Sullivan JP, Girard L, Augustyn A, Yenerall P, Rodriguez-Canales J, Liu H, Behrens C, Shay JW, Wistuba, II and Minna JD. Essential role of aldehyde dehydrogenase $1 \mathrm{~A} 3$ for the maintenance of non-small cell lung cancer stem cells is associated with the STAT3 pathway. Clinical cancer research : an official journal of the American Association for Cancer Research. 2014; 20:4154-4166.

31. Carro MS, Lim WK, Alvarez MJ, Bollo RJ, Zhao X,
Snyder EY, Sulman EP, Anne SL, Doetsch F, Colman H, Lasorella A, Aldape K, Califano A and Iavarone A. The transcriptional network for mesenchymal transformation of brain tumours. Nature. 2010; 463:318-325.

32. Chaturvedi MM, Sung B, Yadav VR, Kannappan R and Aggarwal BB. NF-kappaB addiction and its role in cancer: 'one size does not fit all'. Oncogene. 2011; 30:1615-1630.

33. Grivennikov SI and Karin M. Inflammation and oncogenesis: a vicious connection. Current opinion in genetics \& development. 2010; 20:65-71.

34. Grivennikov SI and Karin M. Dangerous liaisons: STAT3 and NF-kappaB collaboration and crosstalk in cancer. Cytokine \& growth factor reviews. 2010; 21:11-19.

35. Cioce M, Canino C, Pulito C, Muti P, Strano S and Blandino G. Butein impairs the protumorigenic activity of malignant pleural mesothelioma cells. Cell cycle. 2012; 11:132-140.

36. Yu H and Jove R. The STATs of cancer--new molecular targets come of age. Nature reviews Cancer. 2004; 4:97105.

37. Pandey MK, Sung B, Ahn KS and Aggarwal BB. Butein suppresses constitutive and inducible signal transducer and activator of transcription (STAT) 3 activation and STAT3regulated gene products through the induction of a protein tyrosine phosphatase SHP-1. Molecular pharmacology. 2009; 75:525-533.

38. Carpenter RL and Lo HW. STAT3 Target Genes Relevant to Human Cancers. Cancers. 2014; 6:897-925.

39. Oh YT, Yue P, Zhou W, Balko JM, Black EP, Owonikoko TK, Khuri FR and Sun SY. Oncogenic Ras and B-Raf proteins positively regulate death receptor 5 expression through co-activation of ERK and JNK signaling. The Journal of biological chemistry. 2012; 287:257-267.

40. Nozaki S, Sledge Jr GW and Nakshatri H. Repression of GADD153/CHOP by NF-kappaB: a possible cellular defense against endoplasmic reticulum stress-induced cell death. Oncogene. 2001; 20:2178-2185.

41. Mujoomdar AA, Tilleman TR, Richards WG, Bueno R and Sugarbaker DJ. Prevalence of in vitro chemotherapeutic drug resistance in primary malignant pleural mesothelioma: result in a cohort of 203 resection specimens. The Journal of thoracic and cardiovascular surgery. 2010; 140:352-355.

42. Ginestier C, Hur MH, Charafe-Jauffret E, Monville F, Dutcher J, Brown M, Jacquemier J, Viens P, Kleer CG, Liu S, Schott A, Hayes D, Birnbaum D, Wicha MS and Dontu G. ALDH1 is a marker of normal and malignant human mammary stem cells and a predictor of poor clinical outcome. Cell stem cell. 2007; 1:555-567.

43. Antoon JW, White MD, Slaughter EM, Driver JL, Khalili HS, Elliott S, Smith CD, Burow ME and Beckman BS. Targeting NFkB mediated breast cancer chemoresistance through selective inhibition of sphingosine kinase-2. Cancer biology \& therapy. 2011; 11:678-689.

44. Han Z, Feng J, Hong Z, Chen L, Li W, Liao S, Wang X, Ji T, Wang S, Ma D, Chen G and Gao Q. Silencing of 
the STAT3 signaling pathway reverses the inherent and induced chemoresistance of human ovarian cancer cells. Biochemical and biophysical research communications. 2013; 435:188-194.

45. Liu P, Brown S, Goktug T, Channathodiyil P, Kannappan V, Hugnot JP, Guichet PO, Bian X, Armesilla AL, Darling $\mathrm{JL}$ and Wang W. Cytotoxic effect of disulfiram/copper on human glioblastoma cell lines and ALDH-positive cancerstem-like cells. British journal of cancer. 2012; 107:14881497.

46. Stankovic T and Marston E. Molecular mechanisms involved in chemoresistance in paediatric acute lymphoblastic leukaemia. Srpski arhiv za celokupno lekarstvo. 2008; 136:187-192.

47. Yin Z, Zhang Y, Li Y, Lv T, Liu J and Wang X. Prognostic significance of STAT3 expression and its correlation with chemoresistance of non-small cell lung cancer cells. Acta histochemica. 2012; 114:151-158.

48. Cooper LA, Gutman DA, Chisolm C, Appin C, Kong J, Rong Y, Kurc T, Van Meir EG, Saltz JH, Moreno CS and Brat DJ. The tumor microenvironment strongly impacts master transcriptional regulators and gene expression class of glioblastoma. The American journal of pathology. 2012; 180:2108-2119.

49. Manning CB, Vallyathan V and Mossman BT. Diseases caused by asbestos: mechanisms of injury and disease development. International immunopharmacology. 2002; 2:191-200.

50. Dalton LE, Clarke HJ, Knight J, Lawson MH, Wason J, Lomas DA, Howat WJ, Rintoul RC, Rassl DM and Marciniak SJ. The endoplasmic reticulum stress marker CHOP predicts survival in malignant mesothelioma. British journal of cancer. 2013; 108:1340-1347.

51. Rong R, Montalbano J, Jin W, Zhang J, Garling M, Sheikh MS and Huang Y. Oncogenic Ras-mediated downregulation of Gadd153/CHOP is required for Ras-induced cellular transformation. Oncogene. 2005; 24:4867-4872.

52. Jauhiainen A, Thomsen C, Strombom L, Grundevik P, Andersson C, Danielsson A, Andersson MK, Nerman O, Rorkvist L, Stahlberg A and Aman P. Distinct cytoplasmic and nuclear functions of the stress induced protein DDIT3/ CHOP/GADD153. PloS one. 2012; 7:e33208.

53. Demaria M, Giorgi C, Lebiedzinska M, Esposito G, D’Angeli L, Bartoli A, Gough DJ, Turkson J, Levy DE, Watson CJ, Wieckowski MR, Provero P, Pinton P and Poli V. A STAT3-mediated metabolic switch is involved in tumour transformation and STAT3 addiction. Aging. 2010; 2:823-842.

54. Dupe V, Matt N, Garnier JM, Chambon P, Mark M and Ghyselinck NB. A newborn lethal defect due to inactivation of retinaldehyde dehydrogenase type 3 is prevented by maternal retinoic acid treatment. Proceedings of the National Academy of Sciences of the United States of America. 2003; 100:14036-14041.
55. Sima A, Parisotto M, Mader S and Bhat PV. Kinetic characterization of recombinant mouse retinal dehydrogenase types 3 and 4 for retinal substrates. Biochimica et biophysica acta. 2009; 1790:1660-1664.

56. Raha D, Wilson TR, Peng J, Peterson D, Yue P, Evangelista M, Wilson C, Merchant M and Settleman J. The cancer stem cell marker aldehyde dehydrogenase is required to maintain a drug-tolerant tumor cell subpopulation. Cancer research. 2014; 74:3579-3590.

57. Cojoc M, Peitzsch C, Kurth I, Trautmann F, KunzSchughart LA, Telegeev GD, Stakhovsky EA, Walker JR, Simin K, Lyle S, Fuessel S, Erdmann K, Wirth M, Krause M, Baumann $M$ and Dubrovska A. Aldehyde dehydrogenase is regulated by Beta-catenin/TCF and promotes radioresistance in prostate cancer progenitor cells. Cancer research. 2015.

58. Smink JJ and Leutz A. Instruction of mesenchymal cell fate by the transcription factor C/EBPbeta. Gene. 2012; 497:1017.

59. Banh A, Xiao N, Cao H, Chen CH, Kuo P, Krakow T, Bavan B, Khong B, Yao M, Ha C, Kaplan MJ, Sirjani D, Jensen K, Kong CS, Mochly-Rosen D, Koong AC, et al. A novel aldehyde dehydrogenase-3 activator leads to adult salivary stem cell enrichment in vivo. Clinical cancer research : an official journal of the American Association for Cancer Research. 2011; 17:7265-7272.

60. Pass HI, Stevens EJ, Oie H, Tsokos MG, Abati AD, Fetsch PA, Mew DJ, Pogrebniak HW and Matthews WJ. Characteristics of nine newly derived mesothelioma cell lines. The Annals of thoracic surgery. 1995; 59:835-844.

61. Cioce M, Gherardi S, Viglietto G, Strano S, Blandino G, Muti $\mathrm{P}$ and Ciliberto G. Mammosphere-forming cells from breast cancer cell lines as a tool for the identification of CSC-like- and early progenitor-targeting drugs. Cell cycle. 2010; 9:2878-2887.

62. Cioce M, Canino C, Goparaju C, Yang H, Carbone M and Pass HI. Autocrine CSF-1R signaling drives mesothelioma chemoresistance via AKT activation. Cell death \& disease. 2014; 5:e1167. 